\title{
Linking diet to acne metabolomics, inflammation, and comedogenesis: an update
}

This article was published in the following Dove Press journal:

Clinical, Cosmetic and Investigational Dermatology

15 July 2015

Number of times this article has been viewed

\section{Bodo C Melnik}

Department of Dermatology, Environmental Medicine and Health Theory, University of Osnabrück, Germany

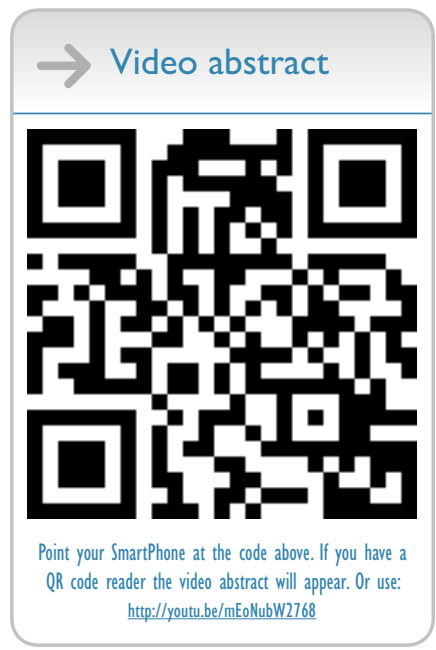

Correspondence: Bodo C Melnik Department of Dermatology, Environmental Medicine and Health Theory, University of Osnabrück, Sedanstrasse I I5, D-49090

Osnabrück, Germany

Tel +4952 41988060

Fax +4952 4I2580I

Email melnik@t-online.de
Abstract: Acne vulgaris, an epidemic inflammatory skin disease of adolescence, is closely related to Western diet. Three major food classes that promote acne are: 1) hyperglycemic carbohydrates, 2) milk and dairy products, 3) saturated fats including trans-fats and deficient $\omega-3$ polyunsaturated fatty acids (PUFAs). Diet-induced insulin/insulin-like growth factor (IGF1)-signaling is superimposed on elevated IGF-1 levels during puberty, thereby unmasking the impact of aberrant nutrigenomics on sebaceous gland homeostasis. Western diet provides abundant branched-chain amino acids (BCAAs), glutamine, and palmitic acid. Insulin and IGF-1 suppress the activity of the metabolic transcription factor forkhead box O1 (FoxO1). Insulin, IGF-1, BCAAs, glutamine, and palmitate activate the nutrient-sensitive kinase mechanistic target of rapamycin complex 1 (mTORC1), the key regulator of anabolism and lipogenesis. FoxO1 is a negative coregulator of androgen receptor, peroxisome proliferator-activated receptor- $\gamma$ $(\operatorname{PPAR} \gamma)$, liver $\mathrm{X}$ receptor- $\alpha$, and sterol response element binding protein-1c (SREBP-1c), crucial transcription factors of sebaceous lipogenesis. mTORC1 stimulates the expression of PPAR $\gamma$ and SREBP-1c, promoting sebum production. SREBP-1c upregulates stearoyl-CoA- and $\Delta 6$-desaturase, enhancing the proportion of monounsaturated fatty acids in sebum triglycerides. Diet-mediated aberrations in sebum quantity (hyperseborrhea) and composition (dysseborrhea) promote Propionibacterium acnes overgrowth and biofilm formation with overexpression of the virulence factor triglyceride lipase increasing follicular levels of free palmitate and oleate. Free palmitate functions as a "danger signal," stimulating toll-like receptor-2-mediated inflammasome activation with interleukin-1 $\beta$ release, Th17 differentiation, and interleukin-17-mediated keratinocyte proliferation. Oleate stimulates $P$. acnes adhesion, keratinocyte proliferation, and comedogenesis via interleukin- $1 \alpha$ release. Thus, diet-induced metabolomic alterations promote the visible sebofollicular inflammasomopathy acne vulgaris. Nutrition therapy of acne has to increase FoxO1 and to attenuate mTORC1/SREBP-1c signaling. Patients should balance total calorie uptake and restrict refined carbohydrates, milk, dairy protein supplements, saturated fats, and trans-fats. A paleolithic-like diet enriched in vegetables and fish is recommended. Plantderived mTORC1 inhibitors and $\omega-3$-PUFAs are promising dietary supplements supporting nutrition therapy of acne vulgaris.

Keywords: acne, comedogenesis, diet, inflammasome, metabolomics, quorum sensing

\section{Introduction}

Based on accumulating indirect translational and in vitro evidence, this review presents an update of the dietary impact on acne metabolomics, follicular inflammation, and comedogenesis. The first part links Western diet to disturbed sebaceous lipogenesis promoted by systemic aberrations of endocrine signaling. To understand the role of nutrigenomics in the pathogenesis of acne, two central players will be highlighted: the role 
of the metabolic transcription factor forkhead box O1A (FoxO1), ${ }^{1-4}$ and the nutrient-sensitive kinase mechanistic target of rapamycin complex 1 (mTORC1). ${ }^{5-8}$ The second part explains the molecular link between disturbed sebofollicular metabolomics and inflammation. The reader will understand that Western diet is the major factor overstimulating sebum production, Propionibacterium acnes overgrowth, and biofilm formation. Biofilm-transformed P. acnes produce abundant exogenous lipase, a virulence factor that increases local levels of free palmitic acid, a recently recognized danger signal activating the NLRP3 inflammasome. Abundance of sebum-derived free palmitate together with $P$. acnes-derived danger-associated molecular patterns (DAMPs) stimulates innate immunity, inflammasome activation, and interleukin- $1 \beta$ (IL-1 $\beta$ )-signaling. IL-1 $\beta$ finally orchestrates follicular and perifollicular inflammation with Th17 cell differentiation and IL-17-mediated local keratinocyte hyperproliferation.

\section{IGF-I: central player of acne}

Most textbooks of dermatology still define acne as an androgen-dependent skin disease. There is no doubt that androgen excess promotes acne and seborrhea, whereas acne does not develop under conditions of androgen receptor (AR) loss of function leading to androgen insensitivity. ${ }^{9}$ These facts clearly point to the involvement of AR-dependent signaling in the pathogenesis of acne. Yet there is still an unsolved contradiction: it is well established that androgen serum levels increase during puberty and stay at high levels for decades, whereas acne physiologically fades spontaneously after puberty. After the climax of puberty, serum levels of insulinlike growth factor 1 (IGF-1), the major growth hormone of puberty, decrease continuously. ${ }^{10}$ Deplewski and Rosenfield ${ }^{11}$ pointed out that not serum androgens but serum IGF-1 levels correlate with the clinical manifestation of acne. Evidence will be presented that not androgens but IGF-1 plays the primary role in acne pathogenesis. IGF-1 signaling is the central endocrine pathway of puberty and sexual maturation, and is the converging point of nutrient signaling in acne.

Which facts do prove this change of paradigms? There is a human experiment of nature supporting the primary role of IGF-1 signaling in acne pathogenesis, the Laron syndrome. Short-statured individuals with Laron syndrome exhibit a congenital IGF-1 deficiency due to growth hormone receptor (GHR) mutations. ${ }^{12}$ Notably, Laron patients, who are not treated with recombinant IGF-1, never develop acne or other common diseases of Western civilization. ${ }^{13,14}$ However, high-dose IGF-1 administration induces acne and hyperandrogenism in these GHR-deficient patients. ${ }^{15}$
The occurrence of hyperandrogenism in IGF-1-treated Laron patients already implies that IGF-1 enhances AR-dependent signal transduction.

\section{IGF-I inhibits FoxO I signaling at multiple regulatory layers}

IGF-1 promotes cell growth and cell proliferation by activating the IGF-1 receptor (IGF1R), resulting in upregulation of the phosphoinositol-3-kinase (PI3K)-protein kinase B (AKT) signaling cascade. ${ }^{16}$ Pioneering autoradiographic studies of Plewig et $\mathrm{al}^{17}$ showed that acne is a hyperproliferative disease of the sebaceous follicle. In acne, increased cell proliferation has been demonstrated in keratinocytes of the acroinfundibulum and ductus seboglandularis, and sebocytes of the sebaceous gland. ${ }^{17}$ Thus, the question arose as to how IGF-1 increases local proliferation of acroinfundibular keratinocytes, epithelial cells of the ductus seboglandularis, and sebocytes. To understand the stimulatory effects of IGF-1 on sebofollicular androgen signaling, it is of critical importance to become familiar with the major regulatory mechanisms that enhance AR transcriptional activity. ${ }^{18,19}$

The AR is a nuclear transcription factor that stimulates the expression of genes that promote androgen-dependent growth and proliferation. ${ }^{18,19}$ AR activation requires two major stimuli: 1) binding of its hormone ligand (androgen), and 2) derepression of its inhibitory nuclear coregulator FoxO1. Ligand-mediated activation of AR depends on androgen binding affinity. Highest AR binding affinity exhibits dihydrotestosterone (DHT), which is ten times higher compared with testosterone. IGF-1 is a potent inducer of gonadal testosterone and adrenal dehydroepiandrosterone (DHEA) synthesis and promotes the intracutaneous conversion of testosterone to DHT by enhancing $5 \alpha$-reductase activity. ${ }^{20,21}$ Thus, IGF-1 increases the total amount of gonadal and adrenal androgen synthesis, ${ }^{22-25}$ and enhances androgen bioactivity by increasing the cutaneous availability of DHT, ${ }^{21}$ the most powerful physiological androgen. Conversely, the androgens induce IGF-1 in the hair follicle. ${ }^{26}$ Thus, IGF-1 stimulates AR signal transduction by upregulating the amount and affinity of AR-activating ligands.

Most dermatologists are not aware of the second most important IGF-1-dependent mechanism that increases AR signaling that involves the metabolic transcription factor FoxO1. In the nucleus, FoxO1 functions as an AR cosuppressor. ${ }^{18,19,27,28}$ Nuclear FoxO1 levels are negatively regulated by insulin and IGF-1. ${ }^{29}$ Both sister hormones activate the PI3K-AKT pathway. ${ }^{20,29}$ Activated AKT phosphorylates FoxO1 in the nucleus, which is the critical step promoting its translocation into the cytoplasm. ${ }^{29}$ 
FoxO1 suppresses AR transactivation by binding to the transcription activation unit 5 (TAU5) located in the AR N-terminal domain (NTD). ${ }^{30}$ The TAU5 motif is most important for androgen-independent activation of the $\mathrm{AR},{ }^{31}$ is controlled by insulin/IGF-1-mediated activation of AKT, and is thus connected to the nutrient status.

Taken together, AR activation requires two different IGF-1-dependent pathways: 1) enhanced ligand potentiation and ligand binding to the AR ligand binding domain and 2) activation of AR transactivation by the nuclear extrusion of the AR suppressor FoxO1 from the NTD. Notably, the NTD contains a polyglutamine-enriched region encoded by $\mathrm{CAG}$ trinucleotide repeats. ${ }^{32}$ Expansion of these CAG repeats in the $\mathrm{AR}$ reduces $\mathrm{AR}$ activation, whereas $A R$ polymorphisms featuring shorter CAG repeats are associated with androgenetic alopecia, hirsutism, and acne. ${ }^{32}$ Individuals featuring AR polymorphisms with shorter $\mathrm{CAG}$ repeats in comparison with individuals with normal CAG repeat length apparently exhibit easier AR hyperactivation by insulin/IGF-1 signaling. These insights also explain increased AR signaling in states of hyperinsulinemia and insulin resistance and conditions with increased IGF-1 serum levels such as puberty and nutrient signaling of Western diet. ${ }^{33}$ Individuals with shorter CAG repeats may thus exhibit stronger acneigenic reactions by dietary exposure to a high glycemic load diet and milk consumption, which both enhance insulin/IGF-1 signaling. ${ }^{20,29}$ My hypothesis of aberrant IGF-1/FoxO1 signaling in the pathogenesis of acne has recently been confirmed experimentally in SZ95 sebocyte cultures. ${ }^{34,35}$ Prolonged IGF-1 exposure of SZ95 sebocytes induced nuclear translocation of FoxO1 into sebocyte's cytoplasm. ${ }^{35}$ Thus, the transcriptional coordinator of metabolism FoxO1 links insulin/IGF-1 signaling to transcriptional activation of AR-dependent target genes. Notably, the highest nuclear FoxO1 activity is observed during starvation, whereas nutrient excess leads to reduced nuclear levels of FoxO1.3,36,37

Serum levels of DHEA, the major adrenal androgen that increases during adrenarche, correlate with the onset of acne vulgaris. ${ }^{38}$ Notably, DHEA induces ERK1/2-mediated phosphorylation and translocation of FoxO1. ${ }^{39}$ Thus, increased adrenal DHEA signaling, which begins prior to puberty, already suppresses FoxO1 activity, increasing AR transactivation. DHEA-induced inactivation of FoxO1 may also explain neonatal hyperseborrhea and acne due to excessive fetal DHEA production, a physiological mechanism ensuring the generation of the vernix caseosa, which is important for birth. ${ }^{40}$

Nuclear FoxO1, which is upregulated by isotretinoin treatment, ${ }^{41}$ controls endocrine signaling of the hypothalamus, ${ }^{42,43}$ pituitary, ${ }^{44}$ liver, ${ }^{45}$ adrenal, ${ }^{46}$ and sebaceous gland.${ }^{34,35,47}$ FoxO1 was recently reported to be an inhibitor of follicle stimulating hormone and luteinizing hormone production. ${ }^{48-50}$ Notably, luteinizing hormone/human chorionic gonadotropin triggers androgen synthesis in theca-interstitial cells of the ovary by activating mTORC1 signaling. ${ }^{51}$ Insulin and IGF-1 act as negative regulators of FoxO1 activity and enhance gonadotropin expression. ${ }^{52}$ Increased insulin/IGF-1 signaling of Western diet thus promotes the synthesis of pituitary gonadotropins, which are pivotal stimuli for gonadal steroidogenesis.

FoxO1 is a negative regulator of GHR, ${ }^{45}$ which plays the key role in hepatic IGF-1 synthesis. ${ }^{12}$ Thus, insulin signaling via repression of hepatic FoxO1 stimulates hepatic IGF-1 synthesis, demonstrating an interactive hepatic network of metabolic and growth factor signaling. Inactivation of hepatic FoxO1 by insulin signaling is required to adapt nutrient homeostasis and endocrine growth regulation. ${ }^{45}$ Notably, isotretinoin, the most powerful antiacne drug, reduced serum concentrations of gonadotropins, adrenocorticotropic hormone, and IGF-1. ${ }^{53-55}$ This can be well explained by isotretinoin-mediated upregulation of nuclear FoxO1 activity at various regulatory levels of the somatotropic axis. ${ }^{41}$

Acne correlates with increased sebum production. GH, insulin, and IGF-1 increase sebaceous gland growth, differentiation, and sebaceous lipogenesis. ${ }^{11,56}$ Vora et $\mathrm{al}^{57}$ observed a linear correlation between serum IGF-1 concentrations and facial sebum excretion rates of male acne patients. Remarkably, increased serum IGF-1 levels have been measured in women with postadolescent acne. ${ }^{58,59}$ Recently, an association between IGF-1 gene polymorphism and acne has been reported.$^{60}$ Patients who observed an aggravation of their acne by food intake exhibited higher IGF-1 serum levels ( mean $=543.9 \mathrm{ng} / \mathrm{mL}$ ) compared with those who observed no acne aggravation by food intake (mean IGF-1 $=391.3 \mathrm{ng} / \mathrm{mL}$ ). ${ }^{61}$

IGF-1 plays a pivotal role in sebaceous lipogenesis. ${ }^{62,63}$ Downstream of IGF-1/PI3K/AKT signaling respond four key lipogenic transcription factors: the AR,,$^{18,19,27,28}$ peroxisome proliferator-activated receptor- $\gamma(\operatorname{PPAR} \gamma),{ }^{64-67}$ liver $\mathrm{X}$ receptor- $\alpha(\mathrm{LXR} \alpha),{ }^{68,69}$ and sterol response element binding protein-1c (SREBP-1c), ${ }^{62,63,70}$ which are all negatively regulated by FoxO1 (Figure 1). ${ }^{18,19,27,28,71-77}$ IGF-1 stimulated SREBP-1 expression and induced lipogenesis in SEB-1 sebocytes via activation of the PI3K/AKT pathway. ${ }^{63}$ Mirdamadi et $\mathrm{al}^{35}$ confirmed that IGF-1 suppresses nuclear FoxO1 in SZ95 sebocytes associated with increased lipogenesis. Under conditions of nutrient excess and high-insulin/IGF-1 signaling, downregulated nuclear FoxO1 thus derepresses all master transcription factors of sebaceous lipogenesis such 


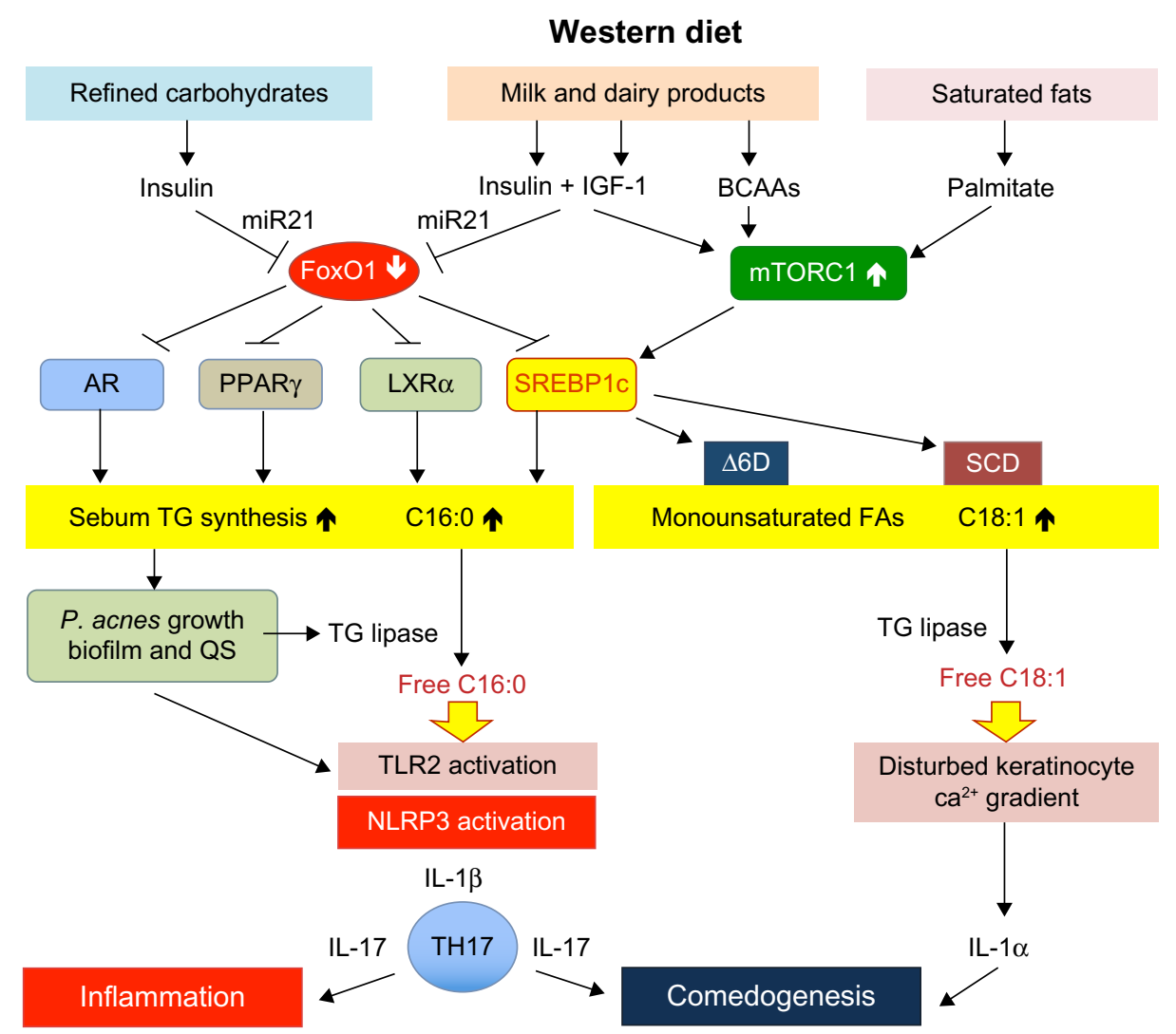

Figure I Acne vulgaris: a Western diet-induced sebofollicular inflammasomopathy.

Abbreviations: IGF-I, insulin-like growth factor I; BCAAs, branched-chain amino acids; miR2I, microRNA-2I; FoxOI, forkhead box class OI; mTORCI, mechanistic target of rapamycin complex I; AR, androgen receptor; PPAR $\gamma$, peroxisome proliferator-activated receptor- $\gamma$; LXR $\alpha$, liver X receptor- $\alpha$; SREBPIc, sterol response element binding protein Ic; $\triangle 6 \mathrm{D}, \Delta 6$-desaturase; SCD, stearoyl-CoA desaturase; TG, triglyceride; $P$. acnes, Propionibacterium acnes; QS, quorum sensing; Cl6:0, palmitic acid; CI8:I, oleic acid; TLR2, toll-like receptor 2; NLRP3, Nod-like receptor family, pyrin domain containing 3 inflammasome; IL-I $\beta$, interleukin-I $\beta$; Th I7, ThI7 T-cell; IL-I7, interleukinI7, IL- $\mid \alpha$, interleukin- I $\alpha$.

as AR, PPAR $\gamma, \mathrm{LXR} \alpha$, and SREBP-1c. In fact, Kwon et $\mathrm{al}^{78}$ observed decreased SREBP-1 expression in facial acne skin after 4 weeks of a low glycemic load diet. Notably, acne-free Kitavan islanders, ${ }^{79}$ who are still exposed to a paleolithic diet (less-hyperglycemic carbohydrates, no milk and dairy products, but plenty of fish intake), exhibit low basal insulin serum levels that are only half of those of Europeans living under conditions of Western neolithic diet. ${ }^{80}$ Incubation of epithelial cells with IGF-1-deficient serum of Laron patients exhibited increased nuclear FoxO1 activity and decreased expression of TOR. ${ }^{14}$ Notably, excessive meat intake is another characteristic feature of Western diet. Recent epidemiological evidence underlines that low protein intake is associated with a major reduction in serum IGF-1 in the middle-aged population. ${ }^{81}$

\section{FoxO I interacts with TGF $\beta$ - and $\beta$-catenin signaling}

McNairn et $\mathrm{al}^{82}$ demonstrated that transforming growth factor- $\beta$ (TGF $\beta$ ) signaling is necessary and sufficient for maintaining sebocytes in an undifferentiated state. TGF $\beta$ receptor type 2 (TGFR2)-SMAD2 signaling decreased the expression of genes required for sebaceous lipogenesis and sebocyte differentiation such as $\Delta 6$-desaturase and PPAR $\gamma$, thereby decreasing sebaceous lipid accumulation. A recent genome-wide association study identified three novel susceptibility loci of the TGF $\beta$ pathway for severe acne vulgaris, namely, transforming growth factor $\beta 2$ (TGFB2), Ovo, Drosophila, homologue-like 1 (OVOL1), and follistatin (FST). ${ }^{83}$ The authors noted a significant reduction in TGFB2 and $O V O L 1$ transcript levels in lesional compared with nonlesional skin of acne patients. ${ }^{83}$

Canonical TGF $\beta$ signaling starts after binding of TGF $\beta$ to TGFR2, which recruits and activates TGFR1. TGFR1 phosphorylates the receptor-bound transcription factors SMAD2 and SMAD3, which later associate with SMAD4. The activated SMAD2/3/4 complex translocates into the nucleus and executes its transcriptional functions. ${ }^{84}$ Importantly, activated SMAD proteins associate with FoxO1, FoxO3, and FoxO4. In human keratinocytes, FoxO-SMAD synexpression plays 
a crucial role in the induction of the cyclin-dependent kinase inhibitors $\mathrm{p} 15$ and $\mathrm{p} 21 .{ }^{85,86}$ Genes that require FoxOSMAD synexpression in response to TGF $\beta$ coordinate cell cycle control via p15 and p21 and adaptive cell signaling responses such as OVOL1 ${ }^{85-87}$ Increased expression of $\mathrm{p} 21$ has been detected in sebocytes treated with isotretinoin, ${ }^{88}$ the most potent antiacne drug that obviously functions as a FoxO1 inducer. ${ }^{41,89}$ Thus, it is conceivable that isotretinoin enhances SMAD-FoxO1-mediated expression of $\mathrm{p} 21$. Western diet with exaggerated insulin/IGF-1 signaling thus affects SMAD-FoxO1-regulated synexpression of important cell cycle checkpoints of keratinocytes and sebocytes. Furthermore, conditional deletion of TGF $\beta$ signaling resulted in PI3K/AKT activation, ${ }^{90}$ the major FoxO1-controlled pathway promoting sebaceous lipogenesis. ${ }^{34}$

FoxO1 interacts with Wingless (Wnt)/ $\beta$-catenin signaling, which blocks differentiation toward the sebocyte phenotype, since inhibition of Wnt target genes promotes sebocyte development. ${ }^{91-93} \beta$-catenin reduces c-Myc-stimulated sebocyte differentiation..$^{94,95}$ Notably, $\beta$-catenin strongly binds FoxO1 and FoxO3a. This interaction enhances FoxO's transcriptional activity. ${ }^{96}$

\section{Fox Os are negative regulators of the nutrient-sensitive kinase mTORCI}

FoxO1 and FoxO3 are negative regulators of the nutrientsensitive kinase mTORC1..$^{97,98}$ mTORC1 has recently been recognized to play a major role in diet-induced acne. ${ }^{47,99,100}$ FoxO1 activates the transcription of the eukaryotic initiation factor 4 binding protein-1 (4EBP-1), which is a major downstream substrate of mTORC1 and functions as a potent translational inhibitor and growth suppressor. ${ }^{101,102}$ Insulin and IGF-1 activate mTORC1, the cell's master regulator orchestrating insulin and IGF-1 signaling, nutrient, glucose, energy, and amino acid availability. ${ }^{103-105}$ Insulin, IGF-1, and amino acids are required for full activation of mTORC1 signaling. The essential branched-chain amino acid (BCAA) leucine plays a primary role in mTORC1 activation. ${ }^{105-107}$ Glutamine, an abundant amino acid constituent of milk proteins, has recently also been demonstrated to have a supportive role in mTORC1 activation. ${ }^{108}$ Leucine and glutamine stimulate mTORC1 by rag GTPase-dependent and independent mechanisms. In contrast to other amino acids, leucine promotes mTORC1 signaling also independent of lysosomal translocation of mTOR. ${ }^{109}$

mTORC1 regulates anabolism, ${ }^{110}$ nutrient-dependent cell cycle progression, ${ }^{111}$ and activates lipogenesis ${ }^{112}$ by inducing the expression and activation of SREBP-1c and PPAR $\gamma .{ }^{113-116}$ Insulin/IGF-1-mediated activation of AKT results in mTORC1 activation. Importantly, mTORC1 phosphorylates and inactivates the negative SREBP-1 regulator lipin $1^{114}$ and promotes gene expression of SREBP-1c. ${ }^{116}$ mTORC1 via activation of the kinase S6K1 promotes SREBP-1c cleavage into its transcriptionally active form. ${ }^{113}$ Thus, several converging mTORC1-dependent pathways enhance the activation of the lipogenic transcription factor SREBP-1c.

\section{SREBP-I c promotes sebum fatty acid desaturation}

It is of critical importance to consider that SREBP-1c is a key regulator of stearoyl-CoA desaturase and $\Delta 6$-desaturase gene expression. Insulin stimulates the expression of $\Delta 6$-desaturase. ${ }^{117,118}$ Stearoyl-CoA desaturase catalyzes the conversion of stearic acid (18:0) to oleic acid (18:1), a major fatty acid of sebum triglycerides. $\Delta 6$-Desaturase and $\Delta 5$-desaturase are key enzymes for the synthesis of highly unsaturated fatty acids such as arachidonic acid, which is the precursor of proinflammatory eicosanoids such as leukotriene B4 (LTB4) and prostaglandin E2 (PGE2) involved in inflammatory responses of sebaceous glands. ${ }^{119}$ Sebocyte $\Delta 6$-desaturase converts palmitic acid (16:0) to sapienic acid $(16: 1),{ }^{120}$ which functions as a natural antimicrobial agent involved in epidermal host defenses. ${ }^{121,122}$ Thus, sebocyte SREBP-1c activity not only controls the total amount of synthesized sebum triglycerides but, via SREBP-1c-mediated gene expression of $\Delta 6$-desaturase and stearoyl-CoA desaturase, increases sebum triglyceride levels of monounsaturated fatty acids. In fact, an association between the synthesis of total sebum triglycerides with increased triglyceride levels of sapienic acid (16:1) and decreased stearic acid (18:0) - due to its conversion to oleic acid (18:1) - has been observed (Figure 1). ${ }^{123}$

FoxO1 is critically involved in the regulation of SREPB1c activity via GHR-mediated hepatic IGF-1 synthesis, ${ }^{45}$ FoxO1-regulated expression of IGF binding protein $1,{ }^{45}$ FoxO1-mediated suppression of LXR $\alpha$, and FoxO1-regulated expression of SREBP-1c. ${ }^{75-77}$ FoxO-mediated inhibition of mTORC1 also controls mTORC1-dependent SREBP-1c expression and its final nuclear activation. ${ }^{113-116}$

\section{Western diet drives acne metabolomics}

High-acne prevalence rates of over $90 \%$ during adolescence, and increasing persistence of acne into the second and third decades of life in around $64 \%$ and $43 \%$ of 
individuals respectively, clearly point to the predominance of environmental and epigenetic factors. ${ }^{124,125}$ Populations exposed to paleolithic dietary conditions (low glycemic load, no milk and dairy consumption) such as the Kitavan islanders of Papua New Guinea, the Ache hunters in Paraguay, the Inuit, and adolescents of rural areas of Brazil are examples of acne-free populations. An increase in acne prevalence has been reported for Inuits, Okinawa islanders, and Chinese after transition from their traditional diets to Westernized nutrition. Accumulating epidemiological, clinical, and translational evidence underlines the impact of nutritional factors in the pathogenesis of common acne vulgaris. Especially nutrients that increase insulin/IGF-1 signaling and thus reduce nuclear FoxO1 levels but enhance mTORC1 have been identified as the most critical inducers of epidemic acne. According to Burris et al, ${ }^{126}$ acne severity in a cohort of New York young adults was associated with: 1) increased intake of sugar (high glycemic load), 2) number of milk servings per day, and 3) amount of saturated fat and trans-fatty acid (TFA) intake. The nutrigenomic impact of these acneigenic food classes will now be discussed in more detail.

\section{Hyperglycemic carbohydrates}

There is a general consensus that a high intake of refined carbohydrates plays a pivotal role in acne pathogenesis. ${ }^{127}$ The effect of high glycemic load diets on the induction and aggravation of acne has been confirmed by several placeboand case-controlled studies. ${ }^{126,128-132}$ A low glycemic load diet increased IGF binding protein 1 (IGFBP1) and IGFBP3, whereas a high glycemic load diet decreased sex hormone binding globulin (SHBG). ${ }^{131}$ Thus, the amount of hyperglycemic carbohydrates modulates the bioactivity of free serum IGF-1 and free serum androgens. Importantly, Kwon et al $^{78}$ observed a decrease of sebaceous gland size and reduced SREBP-1 expression in facial acne skin after 10 weeks of a low glycemic load diet. This metabolic reaction pattern is explained by attenuated AKT-mTORC1 signaling due to carbohydrate reduction with attenuated insulin signaling. Resulting increases of nuclear FoxO1 and decreased mTORC1 activity are in accordance with reduced cutaneous expression of SREBP-1. Decreased cutaneous SREBP-1 expression should not only reduce total sebum production but should also decrease the rate of sebum triglyceride fatty acid desaturation. In fact, a low glycemic load diet increased the ratio of saturated to monounsaturated fatty acids in skin surface triglycerides. ${ }^{133}$ In contrast, increased sebum outflow was associated with an increase in the proportion of monounsaturated fatty acids, thus reflecting SREBP-1-driven total lipogenesis as well as increased SREBP-1c-dependent stimulation of desaturase activity (Figure 1). Thus, a high glycemic load changes the composition of sebum fatty acids, a most critical proinflammatory and comedogenic mechanism that will be discussed later.

There is recent evidence that diet also modifies the expression of microRNAs that play an important role in posttranscriptional regulation of metabolism. ${ }^{134}$ High glucose concentration upregulates microRNA-21 in macrophages. ${ }^{135}$ MicroRNA-21 is a central regulator of cell proliferation and inflammation. ${ }^{136}$ MicroRNA-21 promotes macrophage polarization toward proinflammatory M1 macrophages secreting IL-1 $\beta$, and stimulates Th17 cell differentiation. ${ }^{137,138}$

\section{Milk}

In 1885, Bulkley ${ }^{139}$ reported on acne-aggravating effects of milk consumption in his extensive dietary studies involving 1,500 patients with acne. Harvard epidemiologists Adebamowo et al ${ }^{140-142}$ provided the first epidemiological evidence for the association between milk consumption and acne by evaluating data of the retrospective Nurses' Health Study II and the prospective Growing-up Today Study. Further controlled clinical studies corroborated the milkacne connection. ${ }^{61,129,143}$ A recent semantic connectivity map approach of 563 subjects showed that moderate-to-severe adolescent acne was closely associated with high consumption of milk, in particular, skim milk, cheese/yogurt, sweets/ cakes, chocolate, and a low consumption of fish, and limited intake of fruits/vegetables, ${ }^{144}$ which is the opposite food pattern of paleolithic nutrition.

Milk is a very special functional food designed by evolution to promote anabolism and growth of newborn mammals. To understand milk's impact on acne, it is important to realize that milk promotes anabolic mTORC1 signaling. ${ }^{145}$ To fulfill its growth-promoting function, this secretory product of mammary glands transfers a hardware consisting of amino acids that promote insulin/IGF-1/mTORC1 signaling, and a software delivering exosomal microRNAs, including microRNA-21 that enhances AKT-mTORC1 signal transduction (Figure 1). ${ }^{145}$

Daily consumption of $710 \mathrm{~mL}$ ultra-heat-treated (UHT) milk in prepubertal Mongolian children not used to milk consumption over 4 weeks substantially increased serum GH and IGF-1 levels. ${ }^{146}$ Notably, IGF-1 serum levels increased by $23 \%$ from pretreatment concentrations. These data clearly show that milk consumption switches the somatotropic axis. It is important to realize that it is not the IGF-1 content of cow's milk that exaggerates serum IGF-1 levels of the milk 
consumer, but the milk-driven hepatic production of IGF-1 by the transfer of amino acids that promotes IGF-1 synthesis in the liver of the milk recipient. ${ }^{145}$ Notably, the major whey protein $\alpha$-lactalbumin has the highest tryptophan content among all other protein food sources. ${ }^{147}$ Tryptophan availability is of critical importance for hepatic IGF-1 synthesis. ${ }^{148}$ Milk's essential BCAAs (leucine, isoleucine, and valine) induce pancreatic insulin secretion and explain the high insulinemic index of whole milk and skim milk. ${ }^{149,150}$

Thus, milk intake enhances insulin/IGF-1 signaling. Furthermore, milk proteins transfer high amounts of the insulinotropic amino acid leucine, which promotes mTORC1 activation. ${ }^{145}$ Whey proteins contain the highest amount of leucine (14\%) compared with all other animal proteins such as beef $(8 \%) .{ }^{151}$ In comparison with beef protein $(4.74 \mathrm{~g}$ glutamine/100 g), milk protein (8.09 g glutamine/100 g) contains about twice as much glutamine. ${ }^{152}$ Glutamine not only promotes cellular leucine uptake, ${ }^{153}$ but is the precursor of the glutaminolysis pathway that is critically involved in mTORC1 activation. ${ }^{108,109,154}$ Remarkably, the glutaminolysis pathway plays a special role in sebaceous lipogenesis and sebocyte proliferation. ${ }^{155}$ In freshly isolated human chest sebaceous glands, glutamine deprivation reduced cell proliferation and lipogenesis by $41 \%$ and $37 \%$, respectively. ${ }^{155}$ These data indicate that milk is the ideal fuel for FoxO1/ mTORC1/SREBP-1c-regulated sebaceous gland hyperplasia and sebaceous lipogenesis. Increased IGF-1 production by milk protein intake is thus superimposed on exaggerated IGF-1 signaling of puberty, which explains the earlier onset of puberty and the persistence of acne in the third decade of life in milk-consuming populations.

Analogously to androgen abuse in the bodybuilding environment, excessive milk protein intake has to be considered as a form of doping. ${ }^{156}$ It is of critical concern that milk protein (whey and casein) abuse in the fitness and bodybuilding scenario is associated with the onset and aggravation of acne. ${ }^{157-160}$

The recent prediction of Melnik et al ${ }^{145,149}$ that milk transfers a gene-regulatory metabolically active software consisting of exosomal bioactive microRNAs has recently been confirmed experimentally for cow's milk. ${ }^{161-163}$ Binding of microRNAs through partial sequence homology to the $3^{\prime}$-untranslated region of target mRNAs causes translational block or degradation of target mRNAs. ${ }^{164}$ MicroRNAs, enclosed by membranous microvesicles (exosomes), allow intercellular transfer of microRNAs over long distances. ${ }^{165,166}$ Milk is apparently the exosomal signaling system of mammals that allows maternal-neonatal communication. ${ }^{145,167}$ It is of critical concern that the 245 microRNAs of pasteurized cow's milk are absorbed by humans in biologically meaningful amounts, reach the systemic circulation, and affect the expression of more than the estimated 11,000 genes of the human milk consumer. ${ }^{161}$ In fact, it has been shown that exosomal milk-derived microRNAs are taken up by human cells and modify gene expression. ${ }^{161,163}$ Intriguingly, bovine microRNA-21, a predominant microRNA constituent of cow's milk, is identical to human microRNA-21. ${ }^{168}$ MicroRNA-21 inhibits mRNA expression of phosphatase and tensin homologue (PTEN). ${ }^{169,170} \mathrm{PTEN}$ is a dual protein/ lipid phosphatase. Its main substrate, phosphatidyl-inositol 3,4,5, triphosphate, is the product of PI3K. MicroRNA-21mediated suppression of PTEN mRNA thus promotes PI3K/ AKT signaling, which downregulates nuclear FoxO1. Furthermore, there is recent evidence that microRNA-21 directly targets FoxO1 mRNA. ${ }^{171,172}$ Another recently identified target of microRNA-21 is IGFBP3, ${ }^{173}$ which reduces the bioavailability of IGF-1. The recent observation that exosomal microRNA-21 downregulates the expression of TGF $\beta R 2^{174}$ is of critical importance for acne-prone individuals with a genetic weakness of TGF $\beta$ signaling. ${ }^{83}$ Thus, milk-derived microRNA-21 inhibits FoxO1- as well as TGF $\beta$-signaling at various layers of posttranscriptional regulation.

Danby ${ }^{175}$ emphasized that $75 \%-90 \%$ of marketed commercial milk and milk products in the US are derived from pregnant cows. The milk of these animals contains DHT precursors. During pregnancy, the bovine adrenal gland produces substantial amounts of DHEA, which can be converted to androstenedione via the enzyme $3 \beta$-hydroxysteroid dehydrogenase. Androstenedione levels increase in cow's plasma and milk during pregnancy. ${ }^{176}$ Raw milk of pregnant versus nonpregnant cows contains 3.4 times more androstenedione ( mean $=36.7$ versus $10.9 \mathrm{ng} / \mathrm{dL}$ ), 1.2 times more DHEA (mean $=10.5$ versus $8.7 \mathrm{ng} / \mathrm{dL}$ ), and 1.3 times more testosterone (mean $=10.3$ versus $8.0 \mathrm{ng} / \mathrm{dL}$ ), respectively. ${ }^{177}$ Activation of estrogen receptor beta and AR by the DHEA metabolites androst-5-ene-3,17dione, androst-5-ene-3 $\beta, 17 \beta$-diol, DHT, and $5 \alpha$-androstane$3 \beta, 17 \beta$-diol increased microRNA-21 transcription in HepG2 human hepatoma cells, increasing cell proliferation. ${ }^{178}$ Thus, both milk-derived exosomal microRNA-21 and milk androgen precursor-mediated expression of microRNA-21 may enhance PI3K-AKT-signaling, decreasing FoxO1's nuclear activity. Intriguingly, there has recently been interest in the role of microRNAs as natural ligands of toll-like receptors (TLRs). ${ }^{179}$ MicroRNA-21 and microRNA-29a, both components of cow's milk, can directly bind to TLR8. ${ }^{180}$ TLR8 stimulation activates the inflammasome and upregulates IL-1 $\beta$ secretion. ${ }^{181,182}$ 


\section{Saturated and trans-fats}

Recently, Yasuda et al ${ }^{183}$ provided evidence that the major saturated fatty acid palmitate activates mTORC1 and enhances its lysosomal translocation, whereas the $\omega 3$-fatty acid eicosapentaenoic acid (EPA), a major fatty acid of fish oil, inhibited $\mathrm{mTORC} 1$ activation. It is thus conceivable that sebum-derived free palmitate may activate cell proliferation of acroinfundibular keratinocytes by palmitate-driven mTORC1 signaling, thereby promoting comedogenesis. Notably, palmitate is a major fatty acid, constituting 32\% of milk triglycerides. ${ }^{184,185}$ Burris et al ${ }^{126}$ and Jung et al ${ }^{61}$ observed an aggravation of acne with increased intake of saturated fat, whereas a higher intake of fish, a nutrient source enriched in $\omega 3$-fatty acids, exhibited an acne-protective effect. ${ }^{61,143,144}$

Industrially produced TFAs, which structurally resemble palmitate, are major components of fast food and have been found to aggravate acne. ${ }^{61,126}$ Their mTORC1-activating effect is predictable, but has not yet been studied. These partially hydrogenated fats have displaced natural solid fats and liquid oils in many areas, the most notable ones being in fast food, snack food, fried food, and baked goods that have all been associated with diet-induced acne. ${ }^{61,126}$ In a comparative study of the TFA content of Swedish bakery products in 2007, 3 of 41 products had TFA levels above $2 \%$ of total fatty acids. ${ }^{186}$ However, TFA intakes of Canadian children aged 5-6 years have decreased since 2004 to a $95 \%$ intake of $1.28 \%$ of energy. ${ }^{187}$ TFA intake during pregnancy and lactation of rats increased the expression of TNF receptor-associated factor 6 (TRAF6) in the rat offspring. ${ }^{188}$ Remarkably, TRAF6 mediates IL-1 signaling. ${ }^{189}$ Toll/IL-1 receptor (TIR) domain-containing adaptor protein (TIRAP) is involved in bridging MyD88 to the receptor complex for TLR2 and TLR4 signaling in response to bacterial infection. ${ }^{190}$ Verstak et al ${ }^{190}$ characterized a novel role for TIRAP in facilitating the direct recruitment of TRAF6 to the plasma membrane, which is necessary for TLR2- and TLR4-induced transactivation of NF- $\mathrm{KB}$ and induction of subsequent proinflammatory responses. Thus, Western diet-derived TFA intake via TRAF6-mediated stimulation of proinflammatory TLR2/TLR4 signaling may contribute to nutrient-mediated inflammatory responses of pilosebaceous follicles.

\section{Western diet promotes NRLP3 inflammasome activation}

It has long been known that "sebum is the oil of the acne flame." P. acnes flourishes when sebum production increases. Regional variations in density of $P$. acnes are correlated with sebum secretion. ${ }^{191}$ P. acnes strain 266 , which belongs to the IA (I-1a/ST18) phylotype, is associated with moderate to severe acne and possesses particular virulence potential. ${ }^{192}$ The gehA gene (PPA2105) encoding the secreted triacylglycerol lipase is a virulence factor that is upregulated in P. acnes strain 266 during exponential growth phases. ${ }^{193}$ Recently, P. acnes biofilm formation has been confirmed in sebaceous follicles of acne patients. ${ }^{194}$ Bacteria undergo behavioral and transcriptional changes based on the surrounding bacterial population, a process called quorum sensing (QS). ${ }^{195} \mathrm{QS}$ inhibitors appear to play an important role in the inhibition of biofilm formation. ${ }^{196}$ Biofilm formation substantially increases $P$. acnes virulence associated with enhanced expression of exogenous $P$. acnes triglyceride lipase that increases sebum concentrations of free palmitate and oleate (Figure 1). ${ }^{197,198}$ Zouboulis et al ${ }^{199}$ recently emphasized that not only the total amount of sebum but, predominantly, alterations of sebum lipid composition are main players in the induction of inflammatory acne. Notably, free oleic acid generated by SREBP-1c-dependent stearoyl desaturase and subsequent triacylglycerol lipase-mediated hydrolysis increases P. acnes adherence and growth. ${ }^{200,201}$ Thus, P. acnes lipase may aid colonization and biofilm formation within the pilosebaceous follicle, by promoting oleate-dependent cell adherence. ${ }^{200}$

Innate immunity is activated in acne. Incubation of human keratinocytes with $P$. acnes fractions induced the expression ofTLR2 and TLR4. ${ }^{202}$ Positive TLR2 expression in epidermis, pilosebaceous units, and dermal inflammatory infiltrates has been demonstrated immunohistochemically in acne-involved skin. ${ }^{203}$ Notably, excess saturated fatty acids appear to function as danger signals (DAMPs), ${ }^{204}$ which activate TLR2/ TLR4-driven inflammatory signaling. ${ }^{195}$ Snodgrass et al ${ }^{205}$ recently demonstrated that human monocyte TLR2 activation and inflammasome-mediated secretion of IL- $1 \beta$ are modulated by dietary fatty acids. Remarkably, palmitic acid directly activates TLR2 by inducing heterodimerization with TLR1, whereas docosahexaenoic acid (DHA), a major $\omega 3$-fatty acid of fish oil, inhibited TLR2/TLR1 dimerization. ${ }^{205}$ TLR2/ TLR1 dimerization is thus a most critical palmitate-dependent regulatory mechanism in inflammasome activation resulting in subsequent IL-1 $\beta$ secretion. This molecular mechanism apparently links enhanced levels of free sebum palmitate to TLR2-driven inflammasome activation of the pilosebaceous follicle in acne. There is recent evidence that inflammatory TLR2-NF-KB signaling in macrophages is well enhanced by palmitate. ${ }^{206}$ Sebum free saturated fatty acids apparently promote a TLR-mediated danger response of the sebaceous 
follicle associated with upregulated $\beta$-defensin- 2 expression of human sebocytes. ${ }^{207}$ Palmitate has been recognized as a crucial stimulator of the NLRP3 inflammasome and plays an important role in lipotoxic inflammasome activation of macrophages. ${ }^{208,209}$ In human monocyte/macrophages, both palmitate and stearate triggered IL-1 $\beta$ secretion in a caspase-1/ASC/NLRP3-dependent pathway. ${ }^{210}$ In chondrocytes as well, palmitate synergized with IL- $1 \beta$ in stimulating proinflammatory cellular responses. ${ }^{211}$ Thus, excessive production and release of sebum-derived free palmitic acid appears to be a lipotoxic danger signal of the sebaceous follicle that drives inflammation.

The NLRP3 inflammasome is regarded as a sensor of metabolic danger signals activated by lysosomal rupture, potassium efflux, and reactive oxygen species production. ${ }^{212}$ Kistowska et $\mathrm{al}^{213}$ demonstrated that lysosomal rupture is required for IL-1 $\beta$ secretion in response to P. acnes. Notably, palmitate is known to destabilize lysosomes, leading to NLRP3 inflammasome activation. ${ }^{208}$ Thus, excess saturated fatty acids stimulate and augment a danger response via TLR2 activation and lysosomal destabilization finally processed by the NLRP3 inflammasome that mediates IL-1 $\beta$ signaling (Figure 1). ${ }^{208,214}$ In addition to palmitate, P. acnes itself triggers NLRP3 inflammasome activation of monocyte-macrophages and human sebocytes, increasing IL-1 $\beta$ secretion. ${ }^{213,215,216}$

\section{IL-I $\beta$ release stimulates the Th I 7 response}

IL-1 $\beta$ activates IL-17A positive T cells (Th17 cells) and CD83 dendritic cells in acne lesions, resulting in the activation of Th17-related cytokines. ${ }^{217}$ In addition to IL-17A, both Th1 and Th17 effector cytokines, transcription factors, and chemokine receptors are strongly upregulated in acne lesions. ${ }^{218}$ IL-17A and IL-17F are key cytokines for the recruitment and activation of neutrophils and can target keratinocytes, endothelial cells, monocytes, and fibroblasts to produce proinflammatory mediators such as IL-6, TNF $\alpha$, IL-1 $\beta$, PGE2, nitric oxide, matrix metalloproteinases, and various chemokines. ${ }^{219}$ IL-17-related antimicrobial peptide and CXCL chemokine production with neutrophil attraction in acne lesions are thus important factors triggering the inflammatory infiltrate. There is substantial support for the hypothesis of Lwin et al, ${ }^{195}$ who suggest that $P$. acnes sends no signals or only "safety signals" when present in controlled quantities under commensal conditions, but becomes pathogenic and sends "danger signals" via QS in the form of excessive free fatty acid production, which stimulates TLR2 and
TLR4 as the bacterial population and its virulence increases (Figure 1).

\section{Sebum free fatty acids promote comedogenesis}

Abnormal follicular keratinization is important for comedo formation in acne. Diet-induced changes in sebum quantity and composition may not only induce the inflammation of acne but may also drive the process of comedogenesis. Increased release of the danger signal "free palmitate" activates TLR2/IL- $1 \beta$ signaling of dendritic cells that promote Th17 cell differentiation with increased secretion of IL-17A. ${ }^{220}$ In fact, increased local levels of IL-1 $\beta$ and IL-17A have been detected in lesional acne skin (Figure 1). ${ }^{217}$ IL-17 is a key cytokine that stimulates keratinocyte proliferation via IL-6/STAT3 signaling. ${ }^{221}$ IL-17 contributes to keratinocyte hyperproliferation and attenuates keratinocyte differentiation. ${ }^{222}$ Thus, IL-17 disturbs follicular keratinocyte homeostasis in acne, a comparable mechanism driving keratinocyte hyperproliferation in psoriasis. ${ }^{223}$

Choi et $\mathrm{al}^{224}$ reported that oleic acid applied on the inner surface of the ear of New Zealand White rabbits induced comedones. Permeability barrier disruption in oleic-acidapplied follicular keratinocytes may disrupt the keratinocyte intracellular calcium gradient, leading to keratinocyte proliferation and follicular hyperkeratosis. ${ }^{224}$ In fact, application of oleic acid and palmitoleic acid induced scaly skin, abnormal keratinization, and epidermal hyperplasia. ${ }^{225}$ Furthermore, application of unsaturated fatty acids increased the intracellular calcium concentration of the keratinocytes. Notably, intracellular calcium increase of keratinocytes stimulated by exposure to free oleic acid increased the production of IL-1 $\alpha$ (Figure 1), ${ }^{226}$ which has been implicated in comedogenesis. ${ }^{227-231}$

Taken together, there is compelling evidence that the nutrigenomic changes promoted by Western diet increase the local availability of sebum free palmitic and oleic acid, driving IL-1 $\beta$ - and IL- $1 \alpha-$ mediated comedogenesis. Both cytokines not only play an important role in early- and lateinflammatory responses in acne, ${ }^{232}$ but apparently represent key mediators of comedo formation.

\section{Nutrition therapy of acne}

In 2005, Cordain ${ }^{233,234}$ emphasized the beneficial effects of a paleolithic diet (no hyperglycemic carbohydrates, no milk and dairy products) for the treatment of acne. Today, his dietary recommendations can be interpreted on the basis of nutrigenomic disturbances induced by Western diet. 
Apparently, dietary and pharmacological treatment of acne have a common mode of action: the increase of nuclear FoxO1 and the attenuation of mTORC1 signaling (Table 1). ${ }^{235}$ Natural dietary compounds that either increase FoxO1 or inhibit mTORC1 as well as inflammasome activation are promising agents for the dietary cure of acne. ${ }^{236}$ The acne-preventive effect of fish consumption is well explained by the antiinflammatory effects of $\omega 3$-fatty acids. A preliminary case study showed an overall improvement of acne severity by 12-week daily supplementation of $3 \mathrm{~g}$ fish oil (930 mg EPA). ${ }^{237}$ Dietary supplementation of acne patients with either $2 \mathrm{~g}$ EPA and DHA or borage oil containing $400 \mathrm{mg} \gamma$-linoleic acid significantly decreased inflammatory and noninflammatory acne lesions. ${ }^{235}$ DHA has been demonstrated to inhibit TLR2/ TLR1 dimerization, TLR2 signaling, and thus inflammasome activation. ${ }^{205}$ In fact, DHA reduced macrophage IL- $1 \beta$ production by limiting inflammasome activation. ${ }^{238}$ This inhibition required DHA binding to free fatty acid receptor 4, also known as GPR120/40, which recruits the adapter protein $\beta$-arrestin $1 / 2{ }^{239} \omega 3$ - and $\omega 6$-PUFAs (polyunsaturated fatty acids) are both natural ligands of GPR120/40. ${ }^{240}$ After receptor binding 63-fatty acids inhibited the NLRP3 inflammasome. ${ }^{208,239}$ Remarkably, both the NLRP3 inflammasome and mTORC1 are activated by palmitic acid and inhibited by DHA, respectively. ${ }^{183,208,239}$ Furthermore, PUFAs counteract the activation of SREBP-1c by increasing SREBP-1c proteolytic cleavage and decreasing its mRNA abundance (Table 2). ${ }^{241,242}$
mTORC1 activity is also attenuated by plant-derived natural compounds such as the major green tea polyphenol epigallocatechin-3-gallate (EGCG) and the stilbenol resveratrol. ${ }^{236}$ EGCG suppressed IGF-1-induced lipogenesis, reduced the activation of AKT and mTOR, and attenuated the expression of IL-1, IL-6, and IL-8 in SZ95 sebocytes. ${ }^{243}$ EGCG is a dual PI3K/mTOR inhibitor, and it enhances nuclear FoxO1 and attenuates mTORC1 signaling, ${ }^{244}$ explaining the improvement of acne by topical EGCG treatment. ${ }^{245}$ EGCG has been shown to inhibit SREBP-1 in SEB-1 sebocytes, and improved acne in an 8-week randomized clinical trial with EGCG. ${ }^{244}$ EGCG-mediated activation of AMP-activated kinase is another inhibitory mechanism attenuating mTORC1-SREBP-1 signaling, which explains EGCG-mediated suppression of sebaceous lipogenesis. ${ }^{245}$ These data are in accordance with reduced sebum production of healthy volunteers topically treated with a $3 \%$ green tea emulsion. ${ }^{246}$ Notably, a preliminary case study reported improvement of acne with daily oral intake of $1 \mathrm{~g}$ EPA and 200 mg EGCG (Table 2). ${ }^{247}$

Resveratrol, the polyphenolic flavonoid from grapes and red wine, downregulates $\mathrm{PI}$ K/AKT/mTORC1 signaling. ${ }^{248-252}$ Furthermore, it inhibits the growth of $P$. acnes, ${ }^{253}$ directly inhibits $\mathrm{PI} 3 \mathrm{~K},{ }^{254}$ upregulates FoxO1, and downregulates PPAR $\gamma$ mRNA expression. ${ }^{254}$ Importantly, resveratrol inhibited SZ95 sebocyte growth through inactivation of the PI3K/AKT pathway. ${ }^{255}$ Resveratrol via stimulation of

Table I Acneigenic food components of Western diet

\begin{tabular}{lll}
\hline Nutrients & Metabolic and nutrigenomic effects & Sources \\
\hline Hyperglycemic & Postprandial hyperinsulinemia & Sugar \\
carbohydrates & Insulin-mediated hepatic IGF-I synthesis & Sweets \\
& Reduction of IGFBP3 & Soft drinks \\
Increased bioavailability of free circulating IGF-I & Pizza \\
& Reduction of SHBG & Pasta \\
Increased bioavailability of free circulating testosterone & Wheat bread \\
& Reduced nuclear activity of FoxOI & Wheat rolls \\
Increased expression of sebocyte SREBP-Ic & Cornflakes \\
Activation of mTORCI & Whole and skim milk \\
Milk and dairy & Glucose-mediated microRNA-2I expression & Pasteurized fresh milk \\
products & Postprandial hyperinsulinemia & Yogurt \\
& Increased levels of circulating IGF-I & Ice cream \\
Leucine-mediated activation of mTORCI & Whey and casein supplements \\
Saturated fats & Glutamine-mediated activation of mTORCI & Cheese \\
Trans-fats & Palmitate-mediated activation of mTORCI & Butter \\
& Milk-microRNA-2I-mediated proliferation and inflammation & Cream \\
\hline
\end{tabular}

Abbreviations: IGF-I, insulin-like growth factor I; IGFBP3, IGF binding protein 3; SHBG, sex hormone binding globulin; FoxOI, forkhead box OI; SREBP-Ic, sterol response element binding protein Ic; mTORCI, mechanistic target of rapamycin complex I. 
Table 2 Paleolithic-type diet for the nutrition therapy of acne

\begin{tabular}{|c|c|c|}
\hline Nutrients & Metabolic effects & Sources \\
\hline Carbohydrates with & Reduced insulin signaling & Salads \\
\hline \multirow[t]{5}{*}{ low glycemic index } & Reduction of free IGF-I & Vegetables \\
\hline & Increase of IGFBP3 und SHBG & \\
\hline & Increase of nuclear FoxOI & \\
\hline & Reduction of SREBP-Ic & \\
\hline & Attenuation of mTORCI & \\
\hline$\omega$-3-fatty acids & Inhibition of mTORCI & Sea fish \\
\hline (docosahexaenoic acid & Inhibition of SREBP-Ic & $\omega$-3-fatty acid- \\
\hline \multirow{4}{*}{$\begin{array}{l}\text { and eicosapentaenoic } \\
\text { acid) }\end{array}$} & Reduction of proinflammatory & containing oils \\
\hline & eicosanoids (LTB4, PGE2) & \\
\hline & Inhibition of NRLP3 & \\
\hline & inflammasome activation & \\
\hline Plant products and & Inhibition of mTORCI & Green tea \\
\hline spices enriched in & Activation of nuclear FoxOl & $(E G C G)$ \\
\hline natural mTORCI & Inhibition of $P$. acnes/biofilm & Berries \\
\hline inhibitors and FoxOl & & (resveratrol) \\
\hline enhancers & & Curcumin \\
\hline
\end{tabular}

Abbreviations: IGF-I, insulin-like growth factor I; IGFBP3, IGF binding protein 3; SHBG, sex hormone binding globulin; FoxOI, forkhead box OI; SREBP-Ic, sterol response element binding protein Ic; $\mathrm{mTORCI}$, mechanistic target of rapamycin complex I; LTB4, leukotriene B4; PGE2, prostaglandin E2; EGCG, epigallocatechin3-gallate.

FoxO1 signaling apparently inhibits SREBP-1c. ${ }^{254,256-258}$ In fact, topical treatment of facial acne vulgaris in 20 patients with a resveratrol-containing gel $(0.01 \% \mathrm{wt} / \mathrm{vol})$ significantly reduced the number of microcomedones, papules, and pustules compared with vehicle control. ${ }^{259}$ Furthermore, resveratrol eradicated $P$. acnes biofilm formation (Table 2). ${ }^{260}$

\section{Conclusion}

Food is a conditioning environment that shapes the activity of the human genome. ${ }^{261}$ Acne is obviously the visible outcome of imbalanced nutrigenomics induced by Western diet, the maximized form of neolithic nutrition, that exaggerates insulin/IGF-1 signaling. ${ }^{33}$ Suppression of FoxO1 by Western diet increases the activity of most important transcription factors involved in sebaceous lipogenesis (Figure 1). Upregulated SREBP-1c not only enhances total sebum production but modifies sebum triglyceride fatty acid composition by generating a proinflammatory and comedogenic fatty acid pattern. These metabolomic changes are of critical importance for $P$. acnes overgrowth and biofilm formation and subsequent $P$. acnes-driven inflammation. Oleic acid promotes $P$. acnes adherence, which favors biofilm formation with QS that enhances $P$. acnes virulence by increasing the synthesis of exogenous lipase that releases free palmitic and oleic acid. Free palmitic acid functions as a danger signal that stimulates TLR2-mediated activation of the NLRP3 inflammasome providing proinflammatory IL-1 $\beta$. IL-1 $\beta$ with subsequent
Th17 activation and IL-17 signaling promotes comedogenesis and inflammation.

There is good reason to assume that genetic predispositions to acne increase the acneigenic responsiveness to Western diet. Individuals with persistent insulin resistance, hyperinsulinemia, and hyperandrogenism, such as women with polycystic ovary syndrome (PCOS), will exhibit increased responsiveness to the acneigenic signals of Western diet. ${ }^{262}$ Notably, PCOS responds favorably to metformin, ${ }^{263}$ a recently characterized mTORC1 inhibitor. ${ }^{264}$ Exaggerated mTORC1-S6K1 signaling links acne to increased BMI and insulin resistance. ${ }^{265}$

Androgen abuse has synergistic acneigenic effects with Western diet-driven nutrient signaling, because androgens activate mTORC2 that activates AKT and thus reduces nuclear levels of FoxO1. ${ }^{266,267}$

Nutrient signaling induced by Western diet synergizes with IGF-1 polymorphism associated with increased serum IGF-1 levels, ${ }^{60,268}$ fibroblast growth factor receptor-2 (FGFR2) gain-of-function mutation (Apert syndrome) with increased activation of $\mathrm{AKT},{ }^{269,270} \mathrm{CAG}$ repeat polymorphism with enhanced AR transcriptional activity, ${ }^{32} \mathrm{P} 450$ polymorphisms with accelerated retinoic acid catabolism decreasing nuclear levels of FoxO $1,{ }^{271}$ disturbed TFG $\beta$ signaling impairing FoxO-SMAD-dependent gene synexpression, ${ }^{83-86} \mathrm{IL}-1 \alpha$ polymorphism with increased IL-1 $\alpha$ signaling, ${ }^{272}$ and, finally, the IL-1 $\beta$-producing PAPA (pyogenic arthritis, pyoderma gangrenosum, and acne) syndrome. ${ }^{273-275}$

Epidemic acne vulgaris is an mTORC1-driven systemic disease of Western civilization such as obesity, diabetes, and cancer. ${ }^{47,99,276-278}$ Acne patients should control their total calorie uptake and restrict sugar and refined carbohydrates, milk, whey, and casein protein supplements, saturated fats, and trans-fats. Acne patients should avoid pasteurized fresh milk intake that transfers bioactive microRNA-21, a most critical microRNA that downregulates FoxO1 and promotes inflammation. ${ }^{136,161,162,171,172}$

The ideal "antiacne diet" will be a paleolithic-like nutrition with accentuated intake of vegetables and fruits with low glycemic index and sea fish enriched in anti-inflammatory $\omega 3$-fatty acids. ${ }^{279-281}$ Beneficial and acne-preventive nutrients should contain plant-derived natural mTORC1 inhibitors such as green tea (EGCG), resveratrol, curcumin, genistein, and silymarin (Table 2). ${ }^{236,282-284}$

Western diet obviously induces an IGF-1/mTORC1-driven pilosebaceous inflammasomopathy of adolescence, unmasking a visible metabolic danger signal, which should alert the medical community. Comparable NLRP3-driven reaction patterns have been realized as major pathogenic factors of serious 
diseases of civilization. ${ }^{212}$ The advice of Kapahi et al ${ }^{285}$ "with TOR less is more" apparently applies for the treatment and prevention of the most common diet-induced inflammatory skin disease. Future acne research should determine in vivo mTOR expression and mTORC1-dependent phosphorylation states of S6K1 and 4E-binding protein 1 in acne skin, which could explain the disturbed diet-induced metabolomics in acne skin and their corrections by dietary intervention such as the decreased expression of SREBP and IL-8 in lesional skin of acne patients during a low glycemic load diet. ${ }^{78}$

\section{Acknowledgments}

No sources of funding were used to assist in the preparation of this paper.

\section{Disclosure}

The author reports no conflict of interest in this work.

\section{References}

1. Puig $O$, Tjian R. Nutrient availability and growth: regulation of insulin signaling by dFOXO/FOXO1. Cell Cycle. 2006;5(5):503-505.

2. Kousteni S. FoxO1, the transcriptional chief of staff of energy metabolism. Bone. 2012;50(2):437-443.

3. Gross DN, Wan M, Birnbaum MJ. The role of FOXO in the regulation of metabolism. Curr Diab Rep. 2009;9(3):208-214.

4. Lettieri Barbato D, Aquilano K, Ciriolo MR. FoxO1 at the nexus between fat catabolism and longevity pathways. Biochim Biophys Acta. 2014;1841(10):1555-1560.

5. Gulati P, Thomas G. Nutrient sensing in the mTOR/S6K1 signalling pathway. Biochem Soc Trans. 2007;35(Pt 2):236-238.

6. Dibble CC, Manning BD. Signal integration by mTORC1 coordinates nutrient input with biosynthetic output. Nat Cell Biol. 2013;15(6): $555-564$.

7. Howell JJ, Ricoult SJ, Ben-Sahra I, Manning BD. A growing role for mTOR in promoting anabolic metabolism. Biochem Soc Trans. 2013; 41(4):906-912.

8. Cuyàs E, Corominas-Faja B, Joven J, Menendez JA. Cell cycle regulation by the nutrient-sensing mammalian target of rapamycin (mTOR) pathway. Methods Mol Biol. 2014;1170:113-144.

9. Imperato-McGinley J, Gautier T, Cai LQ, Yee B, Epstein J, Pochi P. The androgen control of sebum production. Studies of subjects with dihydrotestosterone deficiency and complete androgen insensitivity. J Clin Endocrinol Metab. 1993;76(2):524-528.

10. Juul A, Bang P, Hertel NT, et al. Serum insulin-like growth factor-I in 1030 healthy children, adolescents, and adults: relation to age, sex, stage of puberty, testicular size, and body mass index. JClin Endocrinol Metab. 1994;78(3):744-752.

11. Deplewski D, Rosenfield RL. Growth hormone and insulin-like growth factors have different effects on sebaceous cell growth and differentiation. Endocrinology. 1999;140(9):4089-4094.

12. Laron Z, Kowaldo-Silbergeld A, Eshet R, Pertzeln A. Growth hormone resistance. Ann Clin Res. 1980;12(5):269-277.

13. Ben-Amitai D, Laron Z. Effect of insulin-like growth factor-1 deficiency or administration on the occurrence of acne. $J$ Eur Acad Dermatol Venereol. 2011;25(8):950-954.

14. Guevara-Aguirre J, Balasubramanian P, Guevara-Aguirre M, et al. Growth hormone receptor deficiency is associated with a major reduction in pro-aging signaling, cancer, and diabetes in humans. Sci Transl Med. 2011;3(70):70ra13.
15. Klinger B, Anin S, Silbergeld A, Eshet R, Laron Z. Development of hyperandrogenism during treatment with insulin-like growth factor-I (IGF-I) in female patients with Laron syndrome. Clin Endocrinol (Oxf). 1998;48(1):81-87.

16. Denley A, Cosgrove LJ, Booker GW, et al. Molecular interactions of the IGF system. Cytokine Growth Factor Rev. 2005;16(4-5):421-439.

17. Plewig G, Fulton JE, Kligman AM. Cellular dynamics of comedo formation in acne. Arch Dermatol Forsch. 1971;242(1):12-29.

18. Lai JJ, Chang P, Lai KP, Chen L, Chang C. The role of androgen and androgen receptor in the skin-related disorders. Arch Derm Res. 2012;304(7):499-510.

19. Li J, Al-Azzawi F. Mechanism of androgen receptor action. Maturitas. 2009;63(2):142-148.

20. Melnik BC, Schmitz G. Role of insulin, insulin-like growth factor-1, hyperglycaemic food and milk consumption in the pathogenesis of acne vulgaris. Exp Dermatol. 2009;18(10):833-841.

21. Horton R, Pasupuletti V, Antonipillai I. Androgen induction of steroid 5 alpha- reductase may be mediated via insulin-like growth factor-I. Endocrinology. 1993;133(2):447-451.

22. Peters MA, Mol JA, van Wolferen ME, Oosterlaken-Dijksterhuis MA, Teerds KJ, van Sluijs FJ. Expression of the insulin-like growth factor (IGF) system and steroidogenic enzymes in canine testis tumors. Reprod Biol Endocrinol. 2003;1:22.

23. Wang GM, O'Shaughnessy PJ, Chubb C, Robaire B, Hardy MP. Effects of insulin-like growth factor I on steroidogenic enzyme expression levels in mouse leydig cells. Endocrinology. 2003;144(11):5058-5064.

24. Berensztein EB, Baquedano MS, Pepe CM, et al. Role of IGFs and insulin in the human testis during postnatal activation: differentiation of steroidogenic cells. Pediatr Res. 2008;63(6):662-666.

25. Denner L, Bodenburg YH, Jiang J, Pagès G, Urban RJ. Insulin-like growth factor-I activates extracellularly regulated kinase to regulate the p450 side-chain cleavage insulin-like response element in granulosa cells. Endocrinology. 2010;151(6):2819-2825.

26. Inui S, Itami S. Androgen actions on the human hair follicle: perspectives. Exp Dermatol. 2013;22(3):168-171.

27. Fan W, Yanase T, Morinaga H, et al. Insulin-like growth factor 1 /insulin signaling activates androgen signaling through direct interactions of Foxo1 with androgen receptor. J Biol Chem. 2007;282(10):7329-7338.

28. Ma Q, Fu W, Li P, et al. FoxO1 mediates PTEN suppression of androgen receptor $\mathrm{N}$ - and $\mathrm{C}$-terminal interactions and coactivator recruitment. Mol Endocrinol. 2009;23(2):213-225.

29. Van der Heide LP, Hoekman MF, Smidt MP. The ins and outs of FoxO shuttling: mechanisms of FoxO translocation and transcriptional regulation. Biochem J. 2004;380(Pt 2):297-309.

30. Zhao Y, Tindall DJ, Huang H. Modulation of androgen receptor by FOXA1 and FOXO1 factors in prostate cancer. Int J Biol Sci. 2014; 10(6):614-619.

31. Dehm SM, Regan KM, Schmidt LJ, Tindall DJ. Selective role of an NH2-terminal WxxLF motif for aberrant androgen receptor activation in androgen depletion independent prostate cancer cells. Cancer Res. 2007;67(20): 10067-10077.

32. Sawaya ME, Shalita AR. Androgen receptor polymorphisms (CAG repeat lengths) in androgenetic alopecia, hirsutism, and acne. J Cutan Med Surg. 1998;3(1):9-15.

33. Melnik BC, John SM, Schmitz G. Over-stimulation of insulin/IGF-1 signaling by Western diet may promote diseases of civilization: lessons learnt from Laron syndrome. Nutr Metab (Lond). 2011;8:41.

34. Melnik BC. FoxO1 - the key for the pathogenesis and therapy of acne? J Dtsch Dermatol Ges. 2010;8(2):105-111.

35. Mirdamadi YS, Thielitz A, Wiede A, et al. IGF-1 induces nuclear upregulation of p-Akt and controls expression of nuclear transcription factor FoxO1 levels in SZ95 sebocytes. 41th Annual Meeting of the Arbeitsgemeinschaft Dermatologische Forschung (ADF), P098, e17. Exp Dermatol. 2014;23(3):E18.

36. Nemoto S, Fergusson MM, Finkel T. Nutrient availability regulates SIRT1 through a forkhead-dependent pathway. Science. 2004; 306(5704):2105-2108. 
37. Kramer JM, Davidge JT, Lockyer JM, Staveley BE. Expression of Drosophila FOXO regulates growth and can phenocopy starvation. BMC Dev Biol. 2003;3:5.

38. Lucky AW, Biro FM, Huster GA, Leach AD, Morrison JA, Ratterman J. Acne vulgaris in premenarchal girls. An early sign of puberty associated with rising levels of dehydroepiandrosterone. Arch Dermatol. 1994;130(3):308-314.

39. Lindschau C, Kirsch T, Klinge U, Kolkhof P, Peters I, Fiebeler A. Dehydroepiandrosterone-induced phosphorylation and translocation of FoxO1 depend on the mineralocorticoid receptor. Hypertension. 2011;58(3):471-478.

40. Zouboulis CC, Baron JM, Böhm M, et al. Frontiers in sebaceous gland biology and pathology. Exp Dermatol. 2008;17(6):542-551.

41. Melnik BC. Isotretinoin and FoxO1: a scientific hypothesis. Dermatoendocrinol. 2011;3(3):141-165.

42. Sasaki T, Kitamura T. Roles of FoxO1 and Sirt1 in the central regulation of food intake. Endocr J. 2010;57(11):939-946.

43. Yang G, Lim CY, Li C, et al. FoxO1 inhibits leptin regulation of proopiomelanocortin promoter activity by blocking STAT3 interaction with specificity protein 1. J Biol Chem. 2009;284(6):3719-3727.

44. Thackray VG. Fox tales: regulation of gonadotropin gene expression by forkhead transcription factors. Mol Cell Endocrinol. 2014;385(1-2): 62-70.

45. Dong XC, Copps KD, Guo S, et al. Inactivation of hepatic Foxo1 by insulin signaling is required for adaptive nutrient homeostasis and endocrine growth regulation. Cell Metab. 2008;8(1):65-76.

46. Burns KH, Owens GE, Ogbonna SC, Nilson JH, Matzuk MM. Expression profiling analyses of gonadotropin responses and tumor development in the absence of inhibins. Endocrinology. 2003;144(10) 4492-4507.

47. Melnik BC, Zouboulis CC. Potential role of FoxO1 and mTORC1 in the pathogenesis of Western diet-induced acne. Exp Dermatol. 2013;22(5):311-315

48. Arriola DJ, Mayo SL, Skarra DV, Benson CA, Thackray VG. FOXO1 transcription factor inhibits luteinizing hormone $\beta$ gene expression in pituitary gonadotrope cells. J Biol Chem. 2012;287(40): 33424-33435.

49. Choi YS, Lee HJ, Ku CR, et al. FoxO1 is a negative regulator of FSH $\beta$ gene expression in basal and GnRH-stimulated conditions in female Endocrinology. 2014;155(6):2277-2286.

50. Skarra DV, Arriola DJ, Benson CA, Thackray VG. Forkhead box $\mathrm{O} 1$ is a repressor of basal and GnRH-induced Fshb transcription in gonadotropes. Mol Endocrinol. 2013;27(11):1825-1839.

51. Palaniappan M, Menon KM. Luteinizing hormone/human chorionic gonadotropin-mediated activation of mTORC1 signaling is required for androgen synthesis by theca-interstitial cells. Mol Endocrinol. 2012;26(10):1732-1742.

52. Skarra DV, Thackray VG. FOXO1 is regulated by insulin and IGF1 in pituitary gonadotropes. Mol Cell Endocrinol. 2015;405:14-24.

53. Karadag AS, Ertugrul DT, Tutal E, Akin KO. Isotretinoin influences pituitary hormone levels in acne patients. Acta Derm Venereol. 2011; 91(1):31-34

54. Karadag AS, Takci Z, Ertugrul DT, Bilgili SG, Balahoroglu R, Takir M. The effect of different doses of isotretinoin on pituitary hormones Dermatology. 2015;230(4):354-359.

55. Karadag AS, Ertugrul DT, Tutal E, Akin KO. Short-term isotretinoin treatment decreases insulin-like growth factor-1 and insulin-like growth factor binding protein-3 levels: does isotretinoin affect growth hormone physiology? Br J Dermatol. 2010;162(4):798-802.

56. Deplewski D, Rosenfield RL. Role of hormones in pilosebaceous unit development. Endocr Rev. 2000;21(4):363-392.

57. Vora S, Ovhal A, Jerajani H, Nair N, Chakrabortty A. Correlation of facial sebum to serum insulin-like growth factor-1 in patients with acne. Br J Dermatol. 2008;159(4):990-991.

58. Aizawa H, Niimura M. Elevated serum insulin-like growth factor-1 (IGF-1) levels in women with postadolescent acne. J Dermatol. 1995; 22(4):249-252.
59. Cappel M, Mauger D, Thiboutot D. Correlation between serum levels of insulin-like growth factor 1, dehydroepiandrosterone sulfate, and dihydrotestosterone and acne lesion counts in adult women. Arch Dermatol. 2005;141(3):333-338.

60. Tasil L, Turgut S, Kacar N, et al. Insulin-like growth factor-I gene polymorphism in acne vulgaris. J Eur Acad Dermatol Venereol. 2013;27(2): 254-257.

61. Jung JY, Yoon MY, Hong JS, Choi YS, Suh DH. The influence of dietary patterns on acne vulgaris in Koreans. Eur J Dermatol. 2010;20(6): $1-5$.

62. Smith TM, Cong Z, Gilliland KL, Clawson GA, Thiboutot DM. Insulinlike growth factor-1 induces lipid production in human SEB-1 sebocytes via sterol response element-binding protein-1. J Invest Dermatol. 2006;126(6):1226-1232.

63. Smith TM, Gilliland K, Clawson GA, Thiboutot D. IGF-1 induces SREBP-1 expression and lipogenesis in SEB-1 sebocytes via activation of the phosphoinositide 3-kinase/Akt pathway. J Invest Dermatol. 2008; 128(5):1286-1293.

64. Rosenfield RL, Deplewski D, Kentsis A, Ciletti N. Mechanisms of androgen induction of sebocyte differentiation. Dermatology. 1998; 196(1):43-46.

65. Downie MM, Sanders DA, Maier LM, Stock DM, Kealey T. Peroxisome proliferator- activated receptor and farnesoid $\mathrm{X}$ receptor ligands differentially regulate sebaceous differentiation in human sebaceous gland organ cultures in vitro. Br J Dermatol. 2004;151(4):766-775.

66. Dozsa A, Dezso B, Toth BI, et al. PPAR $\gamma$-mediated and arachidonic acid-dependent signaling is involved in differentiation and lipid production of human sebocytes. J Invest Dermatol. 2014;134(4):910-920.

67. Trivedi NR, Cong Z, Nelson AM, et al. Peroxisome proliferator-activated receptors increase human sebum production. J Invest Dermatol. 2006; 126(9):2002-2009.

68. Russell LE, Harrison WJ, Bahta AW, Zouboulis CC, Burrin JM, Philpott MP. Characterization of liver X receptor expression and function in human skin and the pilosebaceous unit. Exp Dermatol. 2007;16(10):844-852.

69. Hong I, Lee MH, Na TY, Zouboulis CC, Lee MO. LXRalpha enhances lipid synthesis in SZ95 sebocytes. J Invest Dermatol. 2008;128(5): 1266-1272.

70. Harrison WJ, Bull JJ, Seltmann H, Zouboulis CC, Philpott MP. Expression of lipogenic factors galectin-12, resistin, SREBP-1, and SCD in human sebaceous glands and cultured sebocytes. $J$ Invest Dermatol. 2007;127(6):1309-1317.

71. Dowell P, Otto TC, Adi S, Lane MD. Convergence of peroxisome proliferator-activated receptor gamma and Foxo1 signaling pathways. J Biol Chem. 2003;278(46):45485-45491.

72. Fan W, Imamura T, Sonoda N, et al. FOXO1 transrepresses peroxisome proliferator-activated receptor gamma transactivation, coordinating an insulin-induced feed-orward response in adipocytes. $J$ Biol Chem. 2009;284(18):12188-12197.

73. Armoni M, Harel C, Karni S, et al. FOXO1 represses peroxisome proliferator- activated receptor-gamma1 and -gamma2 gene promoters in primary adipocytes. A novel paradigm to increase insulin sensitivity. $J$ Biol Chem. 2006;281(29):19881-19891.

74. Qu S, Su D, Altomonte J, et al. PPAR $\alpha$ mediates the hypolipidemic action of fibrates by antagonizing FoxO1. Am J Physiol Endocrinol Metab. 2007;292(2):E421-E434.

75. Kamei Y, Miura S, Suganami T, et al. Regulation of SREBP1c gene expression in skeletal muscle: role of retinoid $\mathrm{X}$ receptor/liver $\mathrm{X}$ receptor and forkhead-O1 transcription factor. Endocrinology. 2008;149(5): 2293-2305.

76. Liu X, Qiao A, Ke Y, et al. FoxO1 represses LXR $\alpha$-mediated transcriptional activity of SREBP-1c promoter in HepG2 cells. FEBS Lett. 2010;584(20):4330-4334.

77. Deng X, Zhang W, O-Sullivan I, et al. FoxO1 inhibits sterol regulatory element-binding protein-1c (SREBP-1c) gene expression via transcription factors Sp1 and SREBP-1c. J Biol Chem. 2012;287(24): 20132-20143 
78. Kwon HH, Yoon JY, Hong JS, Jung JY, Park MS, Suh DH. Clinical and histological effect of a low glycaemic load diet in treatment of acne vulgaris in Korean patients: a randomized, controlled trial. Acta Derm Venereol. 2012;92(3):241-246.

79. Cordain L, Lindeberg S, Hurtado M, Hill K, Eaton SB, Brand-Miller J. Acne vulgaris: a disease of Western civilization. Arch Dermatol. 2002;138(12):1584-1590.

80. Lindeberg S, Eliasson M, Lindahl B, Ahrén B. Low serum insulin in traditional Pacific Islanders - the Kitava Study. Metabolism. 1999; 48(10):1216-1219.

81. Levine ME, Suarez JA, Brandhorst S, et al. Low protein intake is associated with a major reduction in IGF-1, cancer, and overall mortality in the 65 and younger but not older population. Cell Metab. 2014;19(3): 407-417.

82. McNairn AJ, DoucetY, Demaude J, et al. TGF $\beta$ signaling regulates lipogenesis in human sebaceous glands cells. BMC Dermatol. 2013;13:2.

83. Navarini AA, Simpson MA, Weale M, et al. Genome-wide association study identifies three novel susceptibility loci for severe acne vulgaris. Nat Commun. 2014;5:4020.

84. Massagué J, Gomis RR. The logic of TGFbeta signaling. FEBS Lett. 2006;580(12):2811-2820.

85. Arden KC. FoxO: linking new signaling pathways. Mol Cell. 2004; 14(4):416-418.

86. Gomis RR, Alarcón C, He W, et al. A FoxO-Smad synexpression group in human keratinocytes. Proc Natl Acad Sci U S A. 2006;103(34): 12747-12752.

87. Seoane J, Le HV, Shen L, Anderson SA, Massagué J. Integration of Smad and forkhead pathways in the control of neuroepithelial and glioblastoma cell proliferation. Cell. 2004;117(2):211-223.

88. Nelson AM, Gilliland KL, Cong Z, Thiboutot DM. 13-cis retinoic acid induces apoptosis and cell cycle arrest in human SEB-1 sebocytes. $J$ Invest Dermatol. 2006;126(10):2178-2189.

89. Melnik BC. The role of transcription factor FoxO1 in the pathogenesis of acne vulgaris and the mode of isotretinoin action. G Ital Dermatol Venereol. 2010;145(5):559-571.

90. Bian Y, Terse A, Du J, et al. Progressive tumor formation in mice with conditional deletion of TGF-beta signaling in head and neck epithelia is associated with activation of the PI3K/Akt pathway. Cancer Res. 2009;69(14):5918-5926.

91. Merrill BJ, Gat U, DasGupta R, Fuchs E. Tcf3 and Lef1 regulate lineage differentiation of multipotent stem cells in skin. Genes Dev. 2001;15(13):1688-1705

92. Niemann C, Owens DM, Hulsken J, Birchmeier W, Watt FM. Expression of DeltaNLef1 in mouse epidermis results in differentiation of hair follicles into squamous epidermal cysts and formation of skin tumours. Development. 2002;129(1):95-109.

93. Han G, Li AG, Liang YY, et al. Smad7-induced beta-catenin degradation alters epidermal appendage development. Dev Cell. 2006;11(3): 301-312.

94. Niemann C. Differentiation of the sebaceous gland. Dermatoendocrinol. 2009;1(2):64-67.

95. Lo Celso C, Berta MA, Braun KM, et al. Characterization of bipotent epidermal progenitors derived from human sebaceous gland: Contrasting roles of c-myc and $\beta$-catenin. Stem Cells. 2008;26(5):1241-1252.

96. Essers MA, de Vries-Smits LM, Barker N, Polderman PE, Burgering BM, Korswagen HC. Functional interaction of beta-catenin and FOXO in oxidative stress signaling. Science. 2005;308(5725): 1181-1184.

97. Chen CC, Jeon SM, Bhaskar PT, Nogueira V, et al. FoxOs inhibit mTORC1 and activate Akt by inducing the expression of Sestrin3 and Rictor. Dev Cell. 2010;18(4):592-604.

98. Hay N. Interplay between FOXO, TOR, and Akt. Biochim Biophys Acta. 2011;1813(11):1965-1970.

99. Melnik B. Dietary intervention in acne: attenuation of increased mTORC1 signaling promoted by Western diet. Dermatoendocrinol. 2012;4(1):20-32.

100. Melnik BC. The role of mTORC1 in acne pathogenesis and treatment. Exp Rev Dermatol. 2013;8(6):617-622.
101. Jünger MA, Rintelen F, Stocker H, et al. Drosophila forkhead transcription factor FOXO mediates the reduction in cell number associated with reduced insulin signaling. J Biol. 2003;2(3):20.

102. Puig O, Marr MT, Ruhf ML, Tjian R. Control of cell number by Drosophila FOXO: downstream and feedback regulation of the insulin receptor pathway. Genes Dev. 2003;17(16):2006-2020.

103. Foster KG, Fingar DC. Mammalian target of rapamycin (mTOR): conducting the cellular signalling symphony. J Biol Chem. 2010; 285(19):14071-14077.

104. Kim SG, Buel GR, Blenis J. Nutrient regulation of the mTOR complex 1 signaling pathway. Mol Cells. 2013;35(6):463-473.

105. Bar-Peled L, Sabatini DM. Regulation of mTORC1 by amino acids. Trends Cell Biol. 2014;24(7):400-406.

106. Avruch J, Long X, Ortiz-Vega S, Rapley J, Papageorgiou A, Dai N. Amino acid regulation of TOR complex 1. Am J Physiol Endocrinol Metab. 2009;296(4):E592-E602.

107. Dodd KM, Tee AR. Leucine and mTORC1: a complex relationship. Am J Physiol Endocrinol Metab. 2012;302(11):E1329-E1342.

108. Jewell JL, Kim YC, Russell RC, et al. Metabolism. Differential regulation of mTORC1 by leucine and glutamine. Science. 2015;347(6218): 194-198.

109. Averous J, Lambert-Langlais S, Carraro V, et al. Requirement for lysosomal localization of mTOR for its activation differs between leucine and other amino acids. Cell Signal. 2014;26(9): 1918-1927.

110. Chantranupong L, Wolfson RL, Sabatini DM. Nutrient-sensing mechanisms across evolution. Cell. 2015;161(1):67-83.

111. Wang X, Proud CG. Nutrient control of TORC1, a cell-cycle regulator. Cell. 2009;19(6):260-267.

112. Ricoult SJ, Manning BD. The multifaceted role of mTORC1 in the control of lipid metabolism. EMBO Rep. 2013;14(3):242-251.

113. Quinn WJ 3rd, Birnbaum MJ. Distinct mTORC1 pathways for transcription and cleavage of SREBP-1c. Proc Natl Acad Sci U SA. 2012; 109(40):15974-15975.

114. Porstmann T, Santos CR, Lewis C, Griffiths B, Schulze A. A new player in the orchestra of cell growth: SREBP activity is regulated by $\mathrm{mTORC} 1$ and contributes to the regulation of cell and organ size. Biochem Soc Trans. 2009;37(Pt 1):278-283.

115. Lewis CA, Griffiths B, Santos CR, Pende M, Schulze A. Regulation of the SREBP transcription factors by mTORC1. Biochem Soc Trans. 2011;39(2):495-499.

116. Laplante M, Sabatini DM. Regulation of mTORC1 and its impact on gene expression at a glance. J Cell Sci. 2013;126(Pt 8):1713-1719.

117. Nakamura MT, Nara TY. Gene regulation of mammalian desaturases. Biochem Soc Trans. 2002;30(Pt 6):1076-1079.

118. Arbo I, Halle C, Malik D, Brattbakk HR, Johansen B. Insulin induces fatty acid desaturase expression in human monocytes. Scand J Clin Lab Invest. 2011;71(4):330-339.

119. Alestas T, Ganceviciene R, Fimmel S, Müller-Decker K, Zouboulis CC. Enzymes involved in the biosynthesis of leukotriene B4 and prostaglandin E2 are active in sebaceous glands. J Mol Med (Berl). 2006; 84(1):75-87.

120. Ge L, Gordon JS, Hsuan C, Stenn K, Prouty SM. Identification of the delta- 6 desaturase of human sebaceous glands: expression and enzyme activity. J Invest Dermatol. 2003;120(5):707-714.

121. Drake DR, Brogden KA, Dawson DV, Wertz PW. Thematic review series: skin lipids. Antimicrobial lipids at the skin surface. J Lipid Res. 2008;49(1):4-11.

122. Fischer CL, Blanchette DR, Brogden KA, et al. The roles of cutaneous lipids in host defense. Biochim Biophys Acta. 2014;1841(3): 319-322.

123. Akaza N, Akamatsu H, Numata S, et al. Fatty acid compositions of triglycerides and free fatty acids in sebum depend on amount of triglycerides, and do not differ in presence or absence of acne vulgaris. J Dermatol. 2014;41(12):1069-1076.

124. Ghodsi SZ, Orawa H, Zouboulis CC. Prevalence, severity, and severity risk factors of acne in high school pupils: a community-based study. J Invest Dermatol. 2009;129(9):2136-2141. 
125. Bhate K, Williams HC. Epidemiology of acne vulgaris. Br J Dermatol. 2013;168(3):474-485.

126. Burris J, Rietkerk W, Woolf K. Relationships of self-reported dietary factors and perceived acne severity in a cohort of New York young adults. J Acad Nutr Diet. 2014;114(3):384-392.

127. Mahmood SN, Bowe WP. Diet and acne update. Carbohydrates emerge as the main culprit. J Drugs Dermatol. 2014;13(4):428-435.

128. Burris J, Rietkerk W, Woolf K. Acne: the role of medical nutrition therapy. J Acad Nutr Diet. 2013;113(3):416-430.

129. Ismail NH, Manaf ZA, Azizan NZ. High glycemic load diet, milk and ice cream consumption are related to acne vulgaris in Malaysian young adults: a case control study. BMC Dermatol. 2012;12:13.

130. Smith RN, Mann NJ, Braue A, Mäkeläinen H, Varigos GA. A lowglycemic-load diet improves symptoms in acne vulgaris patients: a randomized controlled trial. Am J Clin Nutr. 2007;86(1):107-115.

131. Smith R, Mann N, Mäkeläinen H, Roper J, Braue A, Varigos G. A pilot study to determine the short-term effects of a low glycemic load diet on hormonal markers of acne: a nonrandomized, parallel, controlled feeding trial. Mol Nutr Food Res. 2008;52(6):718-726.

132. Wolkenstein P, Misery L, Amici JM, et al. Smoking and dietary factors associated with moderate-to-severe acne in French adolescents and young adults: results of a survey using a representative sample. Dermatology. 2015;230(1):34-39.

133. Smith RN, Braue A, Varigos GA, Mann NJ. The effect of a low glycemic load diet on acne vulgaris and the fatty acid composition of skin surface triglycerides. J Dermatol Sci. 2008;50(1):41-52.

134. Flowers E, Won GY, Fukuoka Y. MicroRNAs associated with exercise and diet: a systematic review. Physiol Genomics. 2015;47(1): $1-11$.

135. Shang YY, Fang NN, Wang F, et al. MicroRNA-21, induced by high glucose, modulates macrophage apoptosis via programmed cell death 4 . Mol Med Rep. 2015;12(1):463-469.

136. Sheedy FJ. Turning 21: induction of miR-21 as a key switch in the inflammatory response. Front Immunol. 2015;29;6:19.

137. Wang Z, Brandt S, Medeiros A, et al. MicroRNA 21 is a homeostatic regulator of macrophage polarization and prevents prostaglandin E2-mediated M2 generation. PLoS One. 2015;10(2):e0115855.

138. Murugaiyan G, da Cunha AP, Ajay AK, et al. MicroRNA-21 promotes Th17 differentiation and mediates experimental autoimmune encephalomyelitis. J Clin Invest. 2015;125(3):1069-1080.

139. Bulkley LD. Acne, its Etiology, Pathology and Treatment. New York, NY: GP Putnam's Sons; 1885 .

140. Adebamowo CA, Spiegelman D, Danby FW, Frazier AL, Willett WC, Holmes MD. High school dietary dairy intake and teenage acne. J Am Acad Dermatol. 2005;52(2):207-214.

141. Adebamowo CA, Spiegelman D, Berkey CS, et al. Milk consumption and acne in adolescent girls. Dermatol Online J. 2006;12(4):1.

142. Adebamowo CA, Spiegelman D, Berkey CS, et al. Milk consumption and acne in teenaged boys. J Am Acad Dermatol. 2008;58(5): 787-793.

143. Di Landro A, Cazzaniga S, Parazzini F, et al. Family history, body mass index, selected dietary factors, menstrual history, and risk of moderate to severe acne in adolescents and young adults. J Am Acad Dermatol. 2012;67(6):1129-1135.

144. Grossi E, Cazzaniga S, Crotti S, et al. The constellation of dietary factors in adolescent acne: a semantic connectivity map approach. J Eur Acad Dermatol Venereol. Epub December 2, 2014.

145. Melnik BC, John SM, Schmitz G. Milk is not just food but most likely a genetic transfection system activating mTORC1 signaling for postnatal growth. Nutr J. 2013;12:103.

146. Rich-Edwards JW, Ganmaa D, Pollak MN, et al. Milk consumption and the prepubertal somatotropic axis. Nutr J. 2007;6:28.

147. Heine W, Radke M, Wutzke KD, Peters E, Kundt G. Alpha-lactalbumin enriched low-protein infant formulas: a comparison to breast milk feeding. Acta Paediatr. 1996;85(9):1024-1028.

148. Harp JB, Goldstein S, Phillips LS. Nutrition and somatomedin. XXIII. Molecular regulation of IGF-I by amino acid availability in cultured hepatocytes. Diabetes. 1991;40(1):95-101.
149. Melnik BC. The pathogenic role of persistent milk signaling in mTORC1- and milk-microRNA-driven type 2 diabetes mellitus. Curr Diabetes Rev. 2015;11(1):46-62.

150. Hoyt G, Hickey MS, Cordain L. Dissociation of the glycaemic and insulinaemic responses to whole and skimmed milk. $\mathrm{Br} J \mathrm{Nutr}$. 2005;93(2):175-177.

151. Millward DJ, Layman DK, Tomé D, Schaafsma G. Protein quality assessment: impact of expanding understanding of protein and amino acid needs for optimal health. Am J Clin Nutr. 2008;87(5): $1576 \mathrm{~S}-1581 \mathrm{~S}$

152. Lenders CM, Liu S, Wilmore DW, et al. Evaluation of a novel food composition database that includes glutamine and other amino acids derived from gene sequencing data. Eur J Clin Nutr. 2009;63(12): 1433-1439

153. Nicklin P, Bergman P, Zhang B, et al. Bidirectional transport of amino acids regulates mTOR and autophagy. Cell. 2009;136(3):521-534.

154. Duran RV, Oppliger W, Robitaille AM, et al. Glutaminolysis activates Rag-mTORC1 signaling. Mol Cell. 2012;47(3):349-358.

155. Downie MM, Kealey T. Human sebaceous glands engage in aerobic glycolysis and glutaminolysis. Br J Dermatol. 2004;151(2):320-327.

156. Melnik BC. Androgen abuse in the community. Curr Opin Endocrinol Diabetes Obes. 2009;16(3):218-223.

157. Melnik BC. Evidence for acne-promoting effects of milk and other insulinotropic dairy products. Nestle Nutr Workshop Ser Pediatr Program. 2011;67:131-145.

158. Simonart T. Acne and whey protein supplementation among bodybuilders. Dermatology. 2012;225(3):256-258.

159. Silverberg NB. Whey protein precipitating moderate to severe acne flares in 5 teenaged athletes. Cutis. 2012;90(2):70-72.

160. Pontes Tde C, Fernandes Filho GM, Trindade Ade S, Sobral Filho JF. Incidence of acne vulgaris in young adult users of protein-calorie supplements in the city of João Pessoa - PB. An Bras Dermatol. 2013;88(6):907-912.

161. Baier SR, Nguyen C, Xie F, Wood JR, Zempleni J. MicroRNAs are absorbed in biologically meaningful amounts from nutritionally relevant doses of cow milk and affect gene expression in peripheral blood mononuclear cells, HEK-293 kidney cell cultures, and mouse livers. J Nutr. 2014;144(10):1495-1500.

162. Howard KM, Jati Kusuma R, Baier SR, et al. Loss of miRNAs during processing and storage of cow's (Bos taurus) milk. J Agric Food Chem. 2015;63(2):588-592.

163. Izumi H, Tsuda M, Sato Y, et al. Bovine milk exosomes contain microRNA and mRNA and are taken up by human macrophages. J Dairy Sci. 2015;98(5):2920-2933.

164. Ambros V. The functions of animal microRNAs. Nature. 2004; 431(7006):350-355.

165. Ludwig AK, Giebel B. Exosomes: small vesicles participating in intercellular communication. Int J Biochem Cell Biol. 2012;44(1):11-15.

166. Chen X, Liang H, Zhang J, Zen K, Zhang CY. Horizontal transfer of microRNAs: molecular mechanism and clinical applications. Protein Cell. 2012;3(1):28-37.

167. Igaz I, Igaz P. Possible role for microRNAs as inter-species mediators of epigenetic information in disease pathogenesis: is the non-coding dark matter of the genome responsible for epigenetic interindividual or interspecies communication? Med Hypotheses. 2015;84(2): $150-154$

168. Chen X, Gao C, Li H, et al. Identification and characterization of microRNAs in raw milk during different periods of lactation, commercial fluid, and powdered milk products. Cell Res. 2010;20(10): 1128-1137.

169. Meng F, Henson R, Wehbe-Janek H, Ghoshal K, Jacob ST, Patel T. MicroRNA-21 regulates expression of the PTEN tumor suppressor gene in human hepatocellular cancer. Gastroenterology. 2007;133(2): 647-658

170. Han M, Liu M, Wang Y, et al. Antagonism of miR-21 reverses epithelial- mesenchymal transition and cancer stem cell phenotype through AKT/ERK1/2 incactivation by targeting PTEN. PLoS One. 2012;7(6):e39520. 
171. Lei BX, Liu ZH, Li ZJ, Li C, Deng YF. miR-21 induces cell proliferation and suppresses the chemosensitivity in glioblastoma cells via downregulation of FOXO1. Int J Clin Exp Med. 2014;7(8):2060-2066.

172. Song W, Wang L, Wang L, Li Q. Interplay of miR-21 and FoxO1 modulates growth of pancreatic ductal adenocarcinoma. Tumour Biol. 2015. Epub January 27, 2015.

173. Yang CH, Yue J, Pfeffer SR, et al. MicroRNA-21 promotes glioblastoma tumorigenesis by down-regulating insulin-like growth factor-binding protein-3 (IGFBP3). J Biol Chem. 2014;289(36): 25079-25087.

174. Tian T, Zhu YL, Zhou YY, et al. Exosomal uptake through clathrinmediated endocytosis and macropinocytosis and mediating miR-21 delivery. J Biol Chem. 2014;289(32):22258-22267.

175. Danby FW. Acne and milk, the diet myth, and beyond. J Am Acad Dermatol. 2005;52(2):360-362.

176. Gaiani R, Chiesa F, Mattioli M, Nannetti G, Galeati G. Androstenedione and testosterone concentrations in plasma and milk of the cow throughout pregnancy. J Reprod Fertil. 1984;70(1):55-59.

177. Regal P, Cepeda A, Fente C. Development of an LC-MS/MS method to quantify sex hormones in bovine milk and influence of pregnancy in their levels. Food Addit Contam Part A Chem Anal Control Expo Risk Assess. 2012;29(5):770-779.

178. Teng Y, Litchfield LM, Ivanova MM, Prough RA, Clark BJ, Klinge CM. Dehydroepiandrosterone-induces miR-21 transcription in HepG2 cells through estrogen receptor $\beta$ and androgen receptor. Mol Cell Endocrinol. 2014;392(1-2):23-36.

179. Chen X, Liang H, Zhang J, Zen K, Zhang CY. microRNAs are ligands of Toll-like receptors. RNA. 2013;19(6):737-739.

180. Fabbri M, Paone A, Calore F, et al. MicroRNAs bind to Toll-like receptors to induce prometastatic inflammatory response. Proc Natl Acad Sci U S A. 2012;109(31):E2110-E2116.

181. Schwarz H, Posselt G, Wurm P, Ulbing M, Duschl A, Horejs-Hoeck J. TLR8 and NOD signaling synergistically induce the production of IL-1 $\beta$ and IL-23 in monocyte-derived DCs and enhance the expression of the feedback inhibitor SOCS2. Immunobiology. 2013;218(4): $533-542$.

182. Guo H, Gao J, Taxman DJ, Ting JP, Su L. HIV-1 infection induces interleukin-1 $\beta$ production via TLR8 protein-dependent and NLRP3 inflammasome mechanisms in human monocytes. J Biol Chem. 2014; 289(31):21716-21726.

183. Yasuda M, Tanaka Y, Kume S, et al. Fatty acids are novel nutrient factors to regulate mTORC1 lysosomal localization and apoptosis in podocytes. Biochim Biophys Acta. 2014;1842(7):1097-1108.

184. Jensen RG, Ferris AM, Lammi-Keefe CJ. The composition of milk fat. J Dairy Sci. 1991;74(9):3228-3243.

185. Bitman J, Wood DL. Changes in milk fat phospholipids during lactation. J Dairy Sci. 1990;73(5):1208-1216.

186. Trattner S, Becker W, Wretling S, Öhrvik V, Mattisson I. Fatty acid composition of Swedish bakery products, with emphasis on trans-fatty acids. Food Chem. 2015;175:423-430.

187. Mulder KA, Ferdinands AR, Richardson KJ, Innis SM. Sources of trans and saturated fatty acids in the diets of Vancouver children. Can $J$ Diet Pract Res. 2013;74(1):7-13.

188. de Oliveira JL, Oyama LM, Hachul AC, et al. Hydrogenated fat intake during pregnancy and lactation caused increase in TRAF- 6 and reduced AdipoR1 in white adipose tissue, but not in muscle of 21 days old offspring rats. Lipids Health Dis. 2011;10:22.

189. Cao Z, Xiong J, Takeuchi M, Kurama T, Goeddel DV. TRAF6 is a signal transducer for interleukin-1. Nature. 1996;383(6599):443-446.

190. Verstak B, Nagpal K, Bottomley SP, Golenbock DT, Hertzog PJ, Mansell A. MyD88 adapter-like (Mal)/TIRAP interaction with TRAF6 is critical for TLR2- and TLR4-mediated NF-kappaB proinflammatory responses. J Biol Chem. 2009;284(36):24192-24203.

191. McGinley KJ, Webster GF, Ruggieri MR, Leyden JJ. Regional variations in density of cutaneous propionibacteria: correlation of Propionibacterium acnes populations with sebaceous secretion. J Clin Microbiol. 1980;12(5):672-675.
192. Lomholt HB, Kilian M. Population genetic analysis of Propionibacterium acnes identifies a subpopulation and epidemic clones associated with acne. PLoS One. 2010;5(8):e12277.

193. Brzuszkiewicz E, Weiner J, Wollherr A, et al. Comparative genomics and transcriptomics of Propionibacterium acnes. PLoS One. 2011;6(6):e21581.

194. Jahns AC, Lundskog B, Ganceviciene R, et al. An increased incidence of Propionibacterium acnes biofilms in acne vulgaris: a case-control study. Br J Dermatol. 2012;167(1):50-58

195. Lwin SM, Kimber I, McFadden JP. Acne, quorum sensing and danger. Clin Exp Dermatol. 2014;39(2):162-167.

196. Brackman G, Coenye T. Quorum sensing inhibitors as anti-biofilm agents. Curr Pharm Des. 2015;21(1):5-11.

197. Coenye T, Peeters E, Nelis HJ. Biofilm formation by Propionibacterium acnes is associated with increased resistance to antimicrobial agents and increased production of putative virulence factors. Res Microbiol. 2007;158(4):386-392.

198. Miskin JE, Farrell AM, Cunliffe WJ, Holland KT. Propionibacterium acnes, a resident of lipid-rich human skin, produces a $33 \mathrm{kDa}$ extracellular lipase encoded by gehA. Microbiology. 1997;143(Pt 5): 1745-1755.

199. Zouboulis CC, Jourdan E, Picardo M. Acne is an inflammatory disease and alterations of sebum composition initiate acne lesions. J Eur Acad Dermatol Venereol. 2014;28(5):527-532.

200. Gribbon EM, Cunliffe WJ, Holland KT. Interaction of Propionibacterium acnes with skin lipids in vitro. J Gen Microbiol. 1993;139(8): 1745-1751.

201. Ushijima T, Takahashi M, Ozaki Y. Acetic, propionic, and oleic acid as the possible factors influencing the predominant residence of some species of Propionibacterium and coagulase-negative Staphylococcus on normal human skin. Can J Microbiol. 1984;30(5):647-652.

202. Jugeau S, Tenaud I, Knol AC, et al. Induction of toll-like receptors by Propionibacterium acnes. Br J Dermatol. 2005;153(6): 1105-1113.

203. Bakry OA, Samaka RM, Sebika H, Seleit I. Toll-like receptor 2 and P. acnes: do they trigger initial acne vulgaris lesions? Anal Quant Cytopathol Histpathol. 2014;36(2):100-110.

204. Csak T, Ganz M, Pespisa J, Kodys K, Dolganiuc A, Szabo G. Fatty acid and endotoxin activate inflammasomes in mouse hepatocytes that release danger signals to stimulate immune cells. Hepatology. 2011;54(1):133-144.

205. Snodgrass RG, Huang S, Choi IW, Rutledge JC, Hwang DH. Inflammasome-mediated secretion of IL-1 $\beta$ in human monocytes through TLR2 activation; modulation by dietary fatty acids. J Immunol. 2013;191(8):4337-4347.

206. Huang S, Rutkowsky JM, Snodgrass RG, et al. Saturated fatty acids activate TLR-mediated proinflammatory signaling pathways. J Lipid Res. 2012;53(9):2002-2013.

207. Nakatsuji T, Kao MC, Zhang L, Zouboulis CC, Gallo RL, Huang CM. Sebum free fatty acids enhance the innate immune defense of human sebocytes by upregulating beta-defensin-2 expression. J Invest Dermatol. 2010;130(4):985-994.

208. Legrand-Poels S, Esser N, L'homme L, et al. Free fatty acids as modulators of the NLRP3 inflammasome in obesity/type 2 diabetes. Biochem Pharmacol. 2014;92(1):131-141.

209. Weber K, Schilling JD. Lysosomes integrate metabolic-inflammatory cross-talk in primary macrophage inflammasome activation. $\mathrm{J}$ Biol Chem. 2014;289(13):9158-91571.

210. L'homme L, Esser N, Riva L, et al. Unsaturated fatty acids prevent activation of NLRP3 inflammasome in human monocytes/macrophages. J Lipid Res. 2013;54(11):2998-3008.

211. Alvarez-Garcia O, Rogers NH, Smith RG, Lotz MK. Palmitate has proapoptotic and proinflammatory effects on articular cartilage and synergizes with interleukin-1. Arthritis Rheumatol. 2014;66(7): 1779-1788.

212. Schroder K, Zhou R, Tschopp J. The NLRP3 inflammasome: a sensor for metabolic danger? Science. 2010;327(5963):296-300. 
213. Kistowska M, Gehrke S, Jankovic D, et al. IL-1 $\beta$ drives inflammatory responses to Propionibacterium acnes in vitro and in vivo. J Invest Dermatol. 2014;134(3):677-685.

214. Wen H, Gris D, Lei Y, et al. Fatty acid-induced NLRP3-ASC inflammasome activation interferes with insulin signaling. Nat Immunol. 2011;12(5):408-415.

215. Qin M, Pirouz A, Kim MH, Krutzik SR, Garbán HJ, Kim J. Propionibacterium acnes induces IL-1 $\beta$ secretion via the NLRP3 inflammasome in human monocytes. J Invest Dermatol. 2014;134(2): 381-388.

216. Li ZJ, Choi DK, Sohn KC, et al. Propionibacterium acnes activates the NLRP3 inflammasome in human sebocytes. J Invest Dermatol. 2014;134(11):2747-2756.

217. Kelhälä HL, Palatsi R, Fyhrquist N, et al. IL-17/Th17 pathway is activated in acne lesions. PLoS One. 2014;9(8):e105238.

218. Kistowska M, Meier B, Proust T, et al. Propionibacterium acnes promotes Th17 and Th17/Th1 responses in acne patients. $J$ Invest Dermatol. 2015;135(1):110-118.

219. Maddur MS, Miossec P, Kaveri SV, Bayry J. Th17 cells: biology, pathogenesis of autoimmune and inflammatory diseases, and therapeutic strategies. Am J Pathol. 2012;181(1):8-18.

220. Huang G, Wang Y, Chi H. Regulation of Th17 cell differentiation by innate immune signals. Cell Mol Imunnol. 2012;9:287-295.

221. Du F, Nakamura Y, Tan TL, et al. Expression of snail in epidermal keratinocytes promotes cutaneous inflammation and hyperplasia conducive to tumor formation. Cancer Res. 2010;70(24): 10080-10089.

222. Ha HL, Wang H, Pisitkun P, et al. IL-17 drives psoriatic inflammation via distinct, target cell-specific mechanisms. Proc Nat Acad Sci USA 2014;111(33):E3422-E3431.

223. Martin DA, Towne JE, Kricorian G, et al. The emerging role of IL-17 in the pathogenesis of psoriasis: preclinical and clinical findings. J Invest Dermatol. 2013;133(1):17-26.

224. Choi EH, Ahn SK, Lee SH. The changes of stratum corneum interstices and calcium distribution of follicular epithelium of experimentally induced comedones (EIC) by oleic acid. Exp Dermatol. 1997;6(1):29-35.

225. Katsuta Y, Iida T, Inomata S, Denda M. Unsaturated fatty acids induce calcium influx into keratinocytes and cause abnormal differentiation of epidermis. J Invest Dermatol. 2005;124(5):1008-1013.

226. Katsuta Y, Iida T, Hasegawa K, Inomata S, Denda M. Function of oleic acid on epidermal barrier and calcium influx into keratinocytes is associated with $\mathrm{N}$-methyl D-aspartate-type glutamate receptors. $\mathrm{Br}$ J Dermatol. 2009;160(1):69-74.

227. Hammerberg C, Bata-Csorgo Z, Voorhees JJ, Cooper KD. IL-1 and IL-1 receptor antagonist regulation during keratinocyte cell cycle and differentiation in normal and psoriatic epidermis. Arch Dermatol Res. 1998;290(7):367-374.

228. Eady EA, Goodwin CE, Cove JH, Ingham E, Cunliffe WJ. Inflammatory levels of interleukin 1 alpha are present in the majority of open comedones in acne vulgaris. Arch Dermatol. 1991;127(8):1238-1239.

229. Ingham E, Eady EA, Goodwin CE, Cove JH, Cunliffe WJ. Proinflammatory levels of interleukin-1 alpha-like bioactivity are present in the majority of open comedones in acne vulgaris. J Invest Dermatol. 1992;98(6):895-901.

230. Guy R, Green MR, Kealey T. Modeling acne in vitro. J Invest Dermatol. 1996;106(1):176-182.

231. Selway JL, Kurczab T, Kealey T, Langlands K. Toll-like receptor 2 activation and comedogenesis: implications for the pathogenesis of acne. BMC Dermatol. 2013;13:10

232. Thiboutot DM. Inflammasome activation by Propionibacterium acnes: the story of IL-1 in acne continues to unfold. J Invest Dermatol. 2014;134(3):595-597.

233. Cordain L. Implications for the role of diet in acne. Semin Cutan Med Surg. 2005;24(2):84-91.

234. Cordain L. The Dietary Cure for Acne. Fort Collins, CO: Paleo Diet Enterprises; 2006.
235. Melnik BC, Schmitz G. Are therapeutic effects of antiacne agents mediated by activation of FoxO1 and inhibition of mTORC1? Exp Dermatol. 2013;22(7):502-504.

236. Melnik BC. Western-diet mediated mTORC1 signaling in acne, psoriasis, atopic dermatitis, and related disorders of civilization: therapeutic role of plant-derived natural mTORC1 inhibitors. In: Watson RR, Zibadi S, editors. Biocative Dietary Factors and Plant Extracts in Dermatology. New York, NY: Springer Science + Business Media; 2013:397-419.

237. Khayef G, Young J, Burns-Whitmore B, Spalding T. Effects of fish oil supplementation on inflammatory acne. Lipids Health Dis. 2012;11:165

238. Jung JY, Kwon HH, Hong JS, et al. Effect of dietary supplementation with omega-3 fatty acid and gamma-linolenic acid on acne vulgaris: a randomised, double-blind, controlled trial. Acta Derm Venereol. 2014;94(5):521-525

239. Williams-Bey Y, Boularan C, Vural A, et al. Omega-3 free fatty acids suppress macrophage inflammasome activation by inhibiting NF- $\mathrm{KB}$ activation and enhancing autophagy. PLoS One. 2014;9(6):e97957.

240. Mobraten K, Haug TM, Kleiveland CR, Lea T. Omega-3 and omega-6 PUFAs induce the same GPR120-mediated signalling events, but with different kinetics and intensity in Caco-2 cells. Lipids Health Dis. 2013; $12: 101$

241. Xu J, Cho H, O’Malley S, Park JH, Clarke SD. Dietary polyunsaturated fats regulate rat liver sterol regulatory element binding proteins-1 and -2 in three distinct stages and by different mechanisms. $J$ Nutr. 2002;132(11):3333-3339.

242. Kim HJ, Takahashi M, Ezaki O. Fish oil feeding decreases mature sterol regulatory element-binding protein 1 (SREBP-1) by downregulation of SREBP-1c mRNA in mouse liver. A possible mechanism for down-regulation of lipogenic enzyme mRNAs. J Biol Chem. 1999;274(36):25892-25898.

243. Im M, Kim SY, Sohn KC, et al. Epigallocatechin-3-gallate suppresses IGF-I-induced lipogenesis and cytokine expression in SZ95 sebocytes. J Invest Dermatol. 2012;132(12):2700-2708.

244. Van Aller GS, Carson JD, Tang W, et al. Epigallocatechin gallate (EGCG), a major component of green tea, is a dual phosphoinositide-3kinase/mTOR inhibitor. Biochem Biophys Res Commun. 2011;406(2): 194-199.

245. Yoon JY, Kwon HH, Min SU, Thiboutot DM, Suh DH. Epigallocatechin-3gallate improves acne in humans by modulating intracellular molecular targets and inhibiting P. acnes. J Invest Dermatol. 2013;133(2):429-440.

246. Mahmood T, Akhtar N, Khan BA, Khan HM, Saeed T. Outcomes of $3 \%$ green tea emulsion on skin sebum production in male volunteers. Bosn J Basic Med Sci. 2010;10(3):260-264.

247. Rubin MG, Kim K, Logan AC. Acne vulgaris, mental health and omega-3 fatty acids: a report of cases. Lipids Health Dis. 2008;7:36.

248. Jiang H, Shang X, Wu H, et al. Resveratrol downregulates PI3K/Akt/ mTOR signaling pathways in human U251 glioma cells. J Exp Ther Oncol. 2009;8(1):25-33.

249. Brito PM, Devillard R, Negre-Salvayre, et al. Resveratrol inhibits the mTOR mitogenic signaling evoked by oxidized LDL in smooth muscle cells. Atherosclerosis. 2009;205(1):126-134.

250. Lin JN, Lin VC, Rau KM, et al. Resveratrol modulates tumor cell proliferation and protein translation via SIRT1-dependent AMPK activation. J Agric Food Chem. 2010;58(3):1584-1592.

251. Fröjdö S, Cozzone D, Vidal H, Pirola L. Resveratrol is a class IA phosphoinositide 3-kinase inhibitor. Biochem J. 2007;406(3):511-518.

252. Villa-Cuesta E, Boylan JM, Tatar M, Grupposo PA. Resveratrol inhibits protein translation in hepatic cells. PLoS One. 2011;6(12):e29513.

253. Docherty JJ, McEwen HA, Sweet TJ, Bailey E, Booth TD. Resveratrol inhibition of Propionibacterium acnes. J Antimicrob Chemother. 2007;59(6):1182-1184.

254. Costa Cdos S, Rohden F, Hammes TO, et al. Resveratrol upregulated SIRT1, FOXO1, and adiponectin and downregulated PPAR $\gamma 1-3$ mRNA expression in human visceral adipocytes. Obes Surg. 2011;21(3):356-361. 
255. Kim SY, Hyun MY, Go KC, Zouboulis CC, Kim BJ. Resveratrol exerts growth inhibitory effects on human SZ95 sebocytes through the inactivation of the PI3- K/Akt pathway. Int J Mol Med. 2015;35(4): 1042-1050.

256. Wu L, Zhang Y, Ma X, Zhang N, Qin G. The effect of resveratrol on FoxO1 expression in kidneys of diabetic nephropathy rats. Mol Biol Rep. 2012;39(9):9085-9093.

257. Ganjam GK, Dimova EY, Unterman TG, Kietzmann T. FoxO1 and HNF-4 are involved in regulation of hepatic glucokinase gene expression by resveratrol. J Biol Chem. 2009;284(45):30783-30797.

258. Wang GL, Fu YC, Xu WC, Feng YQ, Fang SR, Zhou XH. Resveratrol inhibits the expression of SREBP1 in cell model of steatosis via Sirt1FOXO1 signaling pathway. Biochem Biophys Res Commun. 2009; 380(3):644-649.

259. Fabbrocini G, Staibano S, De Rosa, et al. Resveratrol-containing gel for the treatment of acne vulgaris: a single-blind, vehicle-controlled, pilot study. Am J Clin Dermatol. 2011;12(2):133-141.

260. Coenye T, Brackman G, Rigole P, et al. Eradication of Propionibacterium acnes biofilms by plant extracts and putative identification of icariin, resveratrol and salidroside as active compounds. Phytomedicine. 2012;19(5):409-412.

261. Landecker H. Food as exposure: nutritional epigenetics and the new metabolism. Biosocieties. 2011;6(2):167-194.

262. Mayer SB, Evans WS, Nestler JE. Polycystic ovary syndrome and insulin: our understanding in the past, present and future. Womens Health (Lond Engl). 2015;11(2):137-149.

263. Johnson NP. Metformin use in women with polycystic ovary syndrome. Ann Transl Med. 2014;2(6):56.

264. Melnik BC, Schmitz G. Metformin: an inhibitor of mTORC1 signaling. J Endocrinol Diabetes Obes. 2014;2(2):1029.

265. Melnik BC, John SM, Plewig G. Acne: risk indicator for increased body mass index and insulin resistance. Acta Derm Venereol. 2013; 93(6):644-649.

266. Fang Z, Zhang T, Dizeyi N, et al. Androgen receptor enhances p27 degradation in prostate cancer cells through rapid and selective TORC2 activation. J Biol Chem. 2012;287(3):2090-2098.

267. Heemers HV, Verhoeven G, Swinnen JV. Androgen activation of the sterol regulatory element-binding protein pathway: current insights. Mol Endocrinol. 2006;20(10):2265-2277.

268. Gu F, Schumacher FR, Canzian F, et al. Eighteen insulin-like growth factor pathway genes, circulating levels of IGF-I and its binding protein, and risk of prostate and breast cancer. Cancer Epidemiol Biomarkers Prev. 2010;19(11):2877-2887.

269. Melnik BC. Role of FGFR2-signaling in the pathogenesis of acne. Dermatoendocrinol. 2009;1(3):141-156.

270. Chen W, Obermayer-Pietsch B, Hong JB, et al. Acne-associated syndromes: models for better understanding of acne pathogenesis. J Eur Acad Dermatol Venereol. 2011;25(6):637-646.
271. Melnik BC. The P450 system and mTORC1 signalling in acne. Exp Dermatol. 2014;23(5):318-319.

272. Szabó K, Tax G, Kis K, et al. Interleukin-1A +4845(G\&gt; T) polymorphism is a factor predisposing to acne vulgaris. Tissue Antigens. 2010;76(5):411-415.

273. Smith EJ, Allantaz F, Bennett L, et al. Clinical, molecular, and genetic characteristics of PAPA syndrome: a review. Curr Genomics. 2010;11(7):519-527.

274. Masters SL, Simon A, Aksentijevich I, Kastner DL. Horror autoinflammaticus: the molecular pathophysiology of autoinflammatory disease. Annu Rev Immunol. 2009;27:621-668.

275. Brenner M, Ruzicka T, Plewig G, Thomas P, Herzer P. Targeted treatment of pyoderma gangrnosum in PAPA (pyogenic arthritis, pyoderma gangrenosum and acne) syndrome with the recombinant human interleukin-1 receptor antagonsit anakinra. Br J Dermatol. 2009;161(5):1199-1201.

276. Zoncu R, Efeyan A, Sabatini DM. mTOR: from growth signal integration to cancer, diabetes and ageing. Nat Rev Mol Cell Biol. 2011;12(1): 21-35.

277. Sutcliffe S, Giovannucci E, Isaacs WB, Willett WC, Platz EA. Acne and risk of prostate cancer. Int J Cancer. 2007;121(12):2688-2692.

278. Zhang M, Qureshi AA, Fortner RT, et al. Teenage acne and cancer risk in US women: a prospective cohort study. Cancer. 2015;121(10): 1681-1687.

279. Frassetto LA, Schloetter M, Mietus-Snyder M, Morris RC Jr, Sebastian A. Metabolic and physiologic improvements from consuming a paleolithic, hunter-gatherer type diet. Eur J Clin Nutr. 2009;63(8):947-955.

280. Carrera-Bastos P, Fontes-Villalba M, O’Keefe JH, Linderberg S, Cordain L. The western diet and lifestyle and diseases of civilization. Res Report Clin Cardiol. 2011;2:15-35.

281. Kuipers RS, Joordens JC, Muskiet FA. A multidisciplinary reconstruction of Palaeolithic nutrition that holds promise for the prevention and treatment of diseases of civilisation. Nutr Res Rev. 2012;25(1): 96-129.

282. Gharagozloo M, Javid EN, Rezaei A, Mousavizadeh K. Silymarin inhibits cell cycle progression and mTOR activity in activated human T cells: therapeutic implications for autoimmune diseases. Basic Clin Pharmacol Toxicol. 2013;112(4):251-256.

283. Xiang L, Nakamura Y, Lim YM, et al. Tetrahydrocurcumin extends life span and inhibits the oxidative stress response by regulating the FOXO forkhead transcription factor. Aging (Albany NY). 2011;3(11): 1098-1109.

284. Li ZC, Zhang LM, Wang HB, Ma JX, Sun JZ. Curcumin inhibits lung cancer progression and metastasis through induction of FOXO1. Tumour Biol. 2014;35(1):111-116.

285. Kapahi P, Chen D, Rogers AN, et al. With TOR, less is more: a key role for the conserved nutrient-sensing TOR pathway in aging. Cell Metab. 2010;11(6):453-465.
Clinical, Cosmetic and Investigational Dermatology

\section{Publish your work in this journal}

Clinical, Cosmetic and Investigational Dermatology is an international, peer-reviewed, open access, online journal that focuses on the latest clinical and experimental research in all aspects of skin disease and cosmetic interventions. All areas of dermatology will be covered; contributions will be welcomed from all clinicians and

\section{Dovepress}

basic science researchers globally. This journal is indexed on CAS. The manuscript management system is completely online and includes a very quick and fair peer-review system, which is all easy to use. Visit http://www.dovepress.com/testimonials.php to read real quotes from published authors. 